\title{
A force-theoretic framework for event structure ${ }^{1}$ \\ Bridget Copley, SFL (CNRS/Paris 8) and Heidi Harley, University of Arizona bridget.copley@sfl.cnrs.fr_hharley@email.arizona.edu
}

11 November 2014

\begin{abstract}
We propose an account of dynamic predicates which draws on the notion of force, eliminating reference to events in the linguistic semantics. We treat dynamic predicates as predicates of forces, represented as functions from an initial situation to a final situation that occurs ceteris paribus, that is, if nothing external intervenes. The possibility that opposing forces might intervene to prevent the transition to a given final situation leads us to a novel analysis of non-culminating accomplishment predicates in a variety of languages, including the English progressive. We then apply the force-theoretic framework to the composition of basic Vendlerian eventuality types within a lexical-decomposition syntax. The difference between predicates of forces and predicates of situations is argued to underlie the dynamic/stative contrast, and also to allow for a formal treatment of the difference between be and stay. Consequences for the relationship between language and cognition are discussed.
\end{abstract}

Keywords: Event, state, Davidson, force dynamics, Aktionsarten, progressive aspect, culmination, syntax-semantics interface

Despite the very significant advances in understanding the semantics of eventualities since the Davidsonian revolution, the representation of Accomplishments in ceteris non paribus contexts where the telos is not reached remains problematic. In this paper we propose that nonculminating or defeasible cases of Accomplishments are the base case in a reconceptualized semantics for event structure. The core concept that we use in our reconceptualization is 'force', an input of energy that arises from the objects and properties in a situation. This approach cashes in the intuition behind the traditional (physics) concept of dynamicity, which has been an important descriptor in event semantics but which has not usually been expressly encoded in accounts of the syntax/semantics interface. Force arguments replace event arguments in dynamic predicates, and situation arguments replace event arguments in stative predicates. The resulting type distinction also yields new insight into the distinction between dynamic and stative predicates.

We motivate our use of the concept of force as the answer to the empirical problem of non-culmination. We note that previous attempts to account for non-culmination fall into two general categories: they either assume a causal relation between two subevents and require the additional machinery of possible worlds (e.g., Dowty, 1979), or they treat a non-culminated

\footnotetext{
${ }^{1}$ We would like to express our deep gratitude to the many people and institutions that have contributed to the development of this project, first and foremost to Paul Portner and the L\&P reviewers on multiple rounds of review and revision; the paper has changed and improved enormously as a result of their comments. Although the content may not reflect it at this point, two philosophically-oriented reviews early on helped us refine our understanding of forces greatly. Extensive discussions with many people have also been instrumental; we cannot list them all here but would like to thank especially Jean-Pierre Koenig and Phil Wolff, as well as audiences in Belfast, Göttingen, Nantes, Stuttgart, Tohoku, Toronto, and at the lab Structures Formelles du Langage (CNRS/Paris 8). This research was supported financially in part by the project Causalité dans le Langage et la Cognition of the Fédération Typologie et Universaux Linguistiques (FR 2559) of the CNRS. Remaining deficiencies and errors are of course our own. We would also like to thank Google and Skype for making our collaboration possible à distance.
} 
event as bearing some, possibly scalar, relation to a culminated event, but fail to adequately address the origin of judgments underlying that relation (e.g., Parsons, 1989, 1990). We preserve insights from both of these previous approaches, proposing that there is a kind of causal relation, understood in force-dynamic terms, between two subarguments, but that something like scalarity (i.e., the fact that the endpoint need not be reached) is involved as well. We propose that nonculmination should not be understood as a derived phenomenon, but rather as the basic one: a dynamic verb refers to a force, rather than an event, and the existence of a force does not entail any necessary effect, because forces are naïvely understood to be inherently defeasible and to interact with each other in deterministic ways. To make the link between conceptual forces and semantic type theory, we map conceptual forces to Davidsonian arguments that are functions from an initial situation to a final situation that occurs ceteris paribus.

We demonstrate how this framework encodes the characteristics of familiar verb classes at the syntax-semantics interface, explicating the way in which the syntactic argument structure is interpreted to produce force-theoretic denotations which can express the insights achieved over the past two decades of research into the relationship between argument structure and event structure. We propose strictly compositional denotations for the substructures of change-of-state verbs, incremental theme verbs, manner verbs, resultatives, activity and semelfactive predicates. We argue that the force-theoretic approach can naturally distinguish between agent and causer arguments, and propose an analysis of source-introducing from-PPs.

Finally, the type-theoretic distinction between forces and situations takes center stage, as we examine the consequences of the proposed framework for dynamic predicates (predicates of forces) and stative predicates (predicates of situations) with respect to adverbial selection (as per Katz's 2003 Stative Adverb Gap) and coercion. The framework allows as well for a natural account of predicates that have been resistant to analysis in event-theoretic approaches, namely verbs of maintaining like keep and stay.

\section{Motivating forces}

We begin with a difficulty encountered in the representation of Accomplishments in ceteris non paribus contexts where the telos is not reached. We argue that treating (certain) Davidsonian arguments as referring to forces addresses these issues in a more satisfactory way.

\subsection{A ceteris non paribus problem with Accomplishments}

A popular line of analysis investigating the internal structure of events has concluded that certain events-Vendlerian Accomplishments, most saliently - are composed of two sub-events, chained together in a causal relationship: John opened the door, for example, is argued to have a causing sub-event $\mathrm{e}_{1}$, and a result sub-event $\mathrm{e}_{2}$ of the door being open (other views of Accomplishments, of course, exist, see e.g. Van Valin and LaPolla 1997:118)). Causal event decomposition theories allow a straightforward expression of the insight that John is the Agent of only the first, causing, sub-event, $\mathrm{e}_{1}$; this event then is 'chained' with $\mathrm{e}_{2}$, which is itself related to the Theme (Pustejovsky 1991, 1995, Higginbotham 2000, Folli 2003, Giorgi \& Pianesi 2001, Kratzer 2005, Ramchand 2008, a.o.). The nature of this chain is typically either implicitly or explicitly assumed to be that of a causal relation of the form $\exists \mathrm{e}_{1} \exists \mathrm{e}_{2}: \mathrm{e}_{1}$ CAUSE $\mathrm{e}_{2}$, assuming Dowty's (1979) (admittedly non-neo-Davidsonian) treatment of causation, itself derived from Lewis's (1973) theory. 
If indeed there is a causal relation of this kind in Accomplishments, a problem arises. For $\mathrm{e}_{1}$ to cause $\mathrm{e}_{2}$ in Lewis's theory, both events must exist. This requirement is reflected in the existential binding of $\mathrm{e}_{1}$ and $\mathrm{e}_{2}$. However, there are many cases in natural language where $\mathrm{e}_{1}$ appears to have this kind of causal relation to $\mathrm{e}_{2}$, at least ceteris paribus, but $\mathrm{e}_{2}$ does not neccessarily occur, because ceteris non paribus. We will discuss two such cases here.

The more well-studied of these cases is the so-called "imperfective paradox" in imperfectives and progressives (especially the English progressive; Dowty 1979, Parsons 1989, 1990, Landman 1992, Portner 1998 among many others). It is perfectly possible to say that Mary was painting the dresser without entailing that the result state occurred:

a. \#Mary painted the dresser black, but she didn't finish.

b. Mary was painting the dresser black, but she didn't finish.

Many theories of the progressive have addressed the contrast in (1). One category of theories involves quantification over a normal or "inertial" set of possible worlds or situations, so that $\mathrm{e}_{1}$ causes $\mathrm{e}_{2}$, and $\mathrm{e}_{2}$ indeed exists, but only in these worlds or situations; the actual world or situation need not be in this set. Dowty (1979) was the first to propose this solution, based on a suggestion from David Lewis. However, Dowty was well aware that inertia worlds represented a powerful complication of the model, and therefore adopted them only "reluctantly" (Dowty, 1979: 148). (See also Landman 1992, Bonomi 1997, Portner 1998, Naumann \& Piñon 1997, Abusch 1985, Engelberg 2002, a.o. for possible worlds, Cipria \& Roberts 2000, Del Prete 2012, for possible situations.) This move was a direct consequence of the problematic conjunction of two premises: (a) that Accomplishments have a causal relation, based on Lewis's theory of causation, (b) that the causal relation, as defined by Lewis, requires that the result occur. The adoption of possible worlds does alleviate the problem. However, there are two different strategies that can be used to obviate the problem entirely.

The first strategy, call it "causal skepticism", is to deny premise (a), namely, that there is a causal connection between an $\mathrm{e}_{1}$ and an $\mathrm{e}_{2}$ in Accomplishments. Essentially this position posits the existence of "partial events": an event e can either hold without culminating (hence it is partial) or it can culminate (Vlach 1981, ter Meulen 1985, Bach 1986, Parsons 1989, 1990, Kearns 1991, Landman $1992,{ }^{2}$ Smith 1991, among many others). In these theories, a principle characterizing the intensional relation between partial and total events, where the total event is the normal or inertial continuation of the partial event, is assumed, or, in the case of Landman 1992, defined via possible worlds. Another way to define this principle is via a mapping to a scale along which an event is measured, from the least culminated to the most culminated (Bohnemeyer \& Swift 2006, Koenig \& Chief 2007, Piñon 2008; see also Beavers 2011 a on the 'Affectedness Hierarchy'). A third way to think about the same principle is to map parts of events to thematic roles or objects (e.g., Krifka 1998, Filip 2008). A rather different approach to the causal skepticism strategy, represented by Asher (1992) and Glasbey (1996), is to take the progressive to apply to inferences that speakers and hearers make about utterances. Such theories avoid the problem with Lewis's theory of causation. However, they for the most part give up the straightforward association between agents and initiating events (Krifka 1998 and Filip 2008 excepted), and they all abdicate on the question of how to tell that one event is related to a more maximal or culminated event.

There is a second strategy for avoiding the problem introduced by the two premises

\footnotetext{
${ }^{2}$ As Portner (1998) points out, Landman's theory falls into this category even though it also uses possible worlds.
} 
above, which has not been utilized, as pointed out by Copley \& Wolff, in press. ${ }^{3}$ Namely, one could deny premise (b), that the existence of a causal relation entails that the result occurs. While many theories of causation, similarly to Lewis's 1973 counterfactual theory, propose a causal relation that is result-entailing, ${ }^{4}$ not all of them do. Copley \& Wolff observe that "non-resultentailing" theories of causation exist: namely, probabilistic theories of causation (Reichenbach 1971, Suppes 1970, Eells 1991, e.g.), and force-dynamic theories of causation (e.g. Dowe 2000, Kistler 2006, Mumford \& Anjum 2011). The latter is related to cognitive linguistic treatments of force-dynamics as constituting an important part of verb meaning (Talmy, 1976, 1981, 1985a, 1985b, 1988, 2000, e.g.; Croft 1990, 1991, 1998; Gärdenfors 2004, 2005, 2007); this line of inquiry seems to have developed independently from the philosophical debates on causation. See also Rappaport Hovav and Levin (2001) for a detailed application of the insights provided by a force-dynamic viewpoint to the problem of English resultatives.

In this article we pursue the force-dynamic version of this strategy. As far as the defeasibility of Accomplishments is concerned, our strategy is in a way causation-affirming, to the extent that force dynamics interprets the relation as supervening on physical causal mechanisms, rather than stopping at the level of observational correlations, as scales and probabilities do. However, it should also be palatable to those skeptical of the idea that there is a causal relation in all Accomplishments, since force dynamics describes more relations than just causation. (In fact, among causal skeptics the notion of "force recipient" is often appealed to, usually without formal development, though see Beavers, 2011.) In this paper we develop a syntax-semantics interface theory of Accomplishments based on a force-theoretic perspective, and extend it to the rest of event structure. We thus eschew the use of possible worlds for nonculmination, although we remain agnostic as to whether possible worlds should be used for "true" modals (see also Copley \& Wolff, in press).

Although the problem posed by the English progressive has been the central case in the literature, it is important to note that empirical problems for the two premises above extend beyond the progressive. So-called 'non-culminating accomplishments' pose a very similar problem. In a number of languages, there are constructions that are not imperfectives, in which telic predicates routinely fail to have a culmination entailment, so that the analogue of the sentence in (1a) above, for instance, is acceptable. Malagasy, for example, has an agentive infix, -an-, which according to Travis (2000) indicates the presence of an initiating event and an active Agent, but forms with the infix do not entail the result of the caused event - the occurrence of the result is implied, but defeasible, as described by Travis (2000: 173), and illustrated in (2) below. ${ }^{5}$

$\begin{array}{lllll}\begin{array}{l}\text { namory } \\ \text { pst.Agent.meet }\end{array} & \begin{array}{l}\text { ny ankizy } \\ \text { the children }\end{array} & \begin{array}{l}\text { ny mpampianatra } \\ \text { the teachers }\end{array} \\ \text {...nefa } & \text { tsy } & \text { nanana } & \text { fotoana } & \text { izy. } \\ \text {...but } & \text { neg } & \text { pst.have } & \text { time } & \text { they. }\end{array}$

\footnotetext{
${ }^{3}$ Beavers (2011: 359 note 19), discussing non-result-entailing lexical items, also notes the existence of this type of strategy without making reference to theories of causation per se.

${ }^{4}$ Result-entailing theories include non-probabilistic causal modeling theories as in Pearl, 2000, Woodward, 2009; see also Hobbs 2005 for an application to language, as well as some theories based on energy transfer (Kistler, 2006).

${ }^{5}$ In the data below that we have taken from previous articles, we adopt the author's abbreviations in each case. We will footnote those abbreviations that seem non-self-explanatory. In Dell's 1987 paper, "N" stands for the "neutral" form of the verb and "A" for the "abilitative" form of the verb.
} 
"The teachers gathered the children but they didn't have time." (Travis 2000: 173)

Similarly, the neutral form of the verb in Tagalog does not entail the result, but rather merely implicates it (Schachter \& Otanes 1972, Dell 1987); the result can be explicitly contradicted. ${ }^{6}$

\begin{tabular}{|c|}
\hline $\begin{array}{l}\text { Inalis } \\
\text { N-pf-remove }\end{array}$ \\
\hline
\end{tabular}

ako kaagad ng sabon, kaya hindi ko naalis.

nom-I rapidly gen soap hence not gen-I A-pf-remove

"I tried to remove (lit. 'I removed') the stain, but I ran out of soap, and couldn't."

(Dell 1987: 186)

In the Salish languages St'át'imcets and Skwxwú7mesh, according to Bar-el, Davis, and Matthewson (2005), the culmination of Accomplishments in otherwise unmarked forms is only implicated, not entailed.
a. k'ul'-ún'-lhkan ti
ts'lá7-a, make-TR-1SG.SU DET
basket-DET
t'u7
aoy
t'u7
$\mathrm{kw}$
tsukw-s
but
NEG
just
DET
finish-3POSS
'I made the basket, but it didn't get finished.' (St'át'imcets)

b.

kw John na kw'el-nt-as

DET John RL cook-TR-3ERG

ta skawts

welh

haw

$\mathrm{k}$-as

$7 \mathrm{i}$

CONJ

NEG

IRR-3CNJ

DET potato

'John cooked a potato but never finished.' (Skwxwú7mesh)

(Bar-el, Davis, and Matthewson 2005: 90)

Examples can be mulitplied further, but we will just provide one final one here. KarachayBalkar, a Turkic language spoken in Russia, also has non-culminating accomplishments (Tatevosov 2008):
Kerim
ešik-ni
ac-xan-d $\dot{z}$
alaj boša-ma-ban-dí.
Kerim
door-ACC
open-PFCT-3SG
but
finish-NEG-PFCT-3SG

(Context: The lock is broken, and Kerim tries to open the door.)

Lit. 'Kerim opened the door, but he did not succeed.'

As should be clear from the disparate families represented by these languages, this is not an

\footnotetext{
${ }^{6}$ Notice the different form of the verb naalis, 'A-pf-remove' in the continuation here; this form of the verb carries a completion entailment, i.e. an entailment that $\mathrm{e} 2$ occurs, here explictly negated. In Malagasy there are also two such verb forms, one that entails completion and one that does not (see, e.g. Travis 2000: 172).
} 
isolated phenomenon; indeed it may be the unmarked option crosslinguistically. See Singh (1998) for discussion of similar facts in Hindi, Altshuler (2013) for Hindi and Russian, Giannakidou and Staraki (2010) for Greek, Koenig and Muansuwan (2000) for Thai, Koenig and Chief (2007) for Mandarin, and Paramasivam (1977) for Tamil (the last as cited in Koenig and Chief 2007).

Just as in a progressive, in all of these non-culminating accomplishments the agent does something that normally leads to a result but can still be unsuccessful in getting the intended result to happen. Not surprisingly, analyses of these facts have appealed to the exactly the same technologies as analyses of the progressive. One group of theories exploits possible worlds for the rescue of a result-entailing theory of causation, e.g., Matthewson, (2004), Tatevosov, (2008). We find the possible world approach problematic because it requires a more complicated logical form for the non-culminated case, which runs counter to the observation that cross-linguistically, if either of the two cases is more morphosyntactically marked, it is the culminated case (Copley $\&$ Wolff, in press). The other major group of theories denies that there is a causal relation, and instead relate partial events to culminated events, e.g., Koenig and Chief (2007), Singh (1998), and Altshuler (2013). Dell's (1987) description of Tagalog neutral verbs as denoting a "maneuver" to achieve a "result" is a significant outlier, being a non-result-entailing, forcedynamic strategy, and is very much along the lines of what we will propose.

\subsection{Forces as functions: Interaction and intervention}

The way that we propose to incorporate force dynamics into formal semantics is to understand forces as conceptual entities that are mapped to functions from situations to situations. We say a few words here about how we approach this, before developing the idea further below.

As we have seen, the fact that Lewis's theory is result-entailing is reflected in the existential binding of $\mathrm{e}_{2}$ in the logical form. We have seen that $\mathrm{e}_{2}$ should be introduced into the logical form, and one should be able to refer to it (i.e., it exists, as a possible event), but that its occurrence should not be asserted. We propose to accomplish this by treating the causal link as mapping to a function between an input and an output argument, where the latter is understood to be the unique result that obtains if all else is equal, proceeds normally, etc.; i.e., all the considerations that have gone into defining inertia worlds and the relation between partial and culminated events in the literature. The initial argument is bound existentially, as usual. The output argument, however, is defined as the output when the causal function is applied to the input argument. In this way, the output argument is defined, and thus can be referred to, without having to actually be asserted to occur.

We then might consider the input argument to be $\mathrm{e}_{1}$, and write in our denotations the following statement of the causal link between $\mathrm{e}_{1}$ and $\mathrm{e}_{2}$ :

$$
\mathrm{f}_{\mathrm{CAUSAL}}\left(\mathrm{e}_{1}\right)=\mathrm{e}_{2}
$$

This move could accommodate the cases of non-occurrence of $\mathrm{e}_{2}$ that we address above within an event-chaining view. However, it should be noted that such an account would be successful only to the extent that $\mathrm{f}_{\mathrm{CAUSAL}}$ could be defined at all over events. It is not trivial to ensure that there is a unique result $\mathrm{e}_{2}$ of a given $\mathrm{e}_{1}$. Of course possible worlds could be recruited to define $\mathrm{f}_{\mathrm{CAUSAL}}$, but then face the objection to possible world approaches to non-culmination raised by Copley \& Wolff (in press).

Instead, we propose that the input and output arguments of a causal function are 
situations. The use of situations instead of events will provide for a unique output for any given input to the causal function, allowing the function to be properly defined. The input is an initial situation including all relevant causal conditions--the entities and their properties in the situation. If the input argument is a different $\mathrm{s}_{0}$, a different $\mathrm{s}_{1}$ will result. ${ }^{7}$

$$
\mathrm{f}_{\mathrm{CAUSAL}}\left(\mathrm{s}_{0}\right)=\mathrm{s}_{1}
$$

On this view of the causal relation, the causing event $\mathrm{e}_{1}$ has disappeared from the calculus. What, then, is actually taking us from the initial to the final situation? Formally, it is the causal function that plays this role. The question here arises as to whether it is legitimate to interpret the causal function in some sense as the event.

There is a line of thought associated in large part with a tradition in computer science, that equates events with transitions between static representations of situations, as in motion pictures or comic books (Moens and Steedman 1988, Naumann 2001, Fernando 2004, 2005, ter Meulen 1990). ${ }^{8}$ Dahl (2007) also views events as transitions from one static situation to another. ${ }^{9}$ For causal skeptics, there is no problem with interpreting events as defeasible; Moens and Steedman, 1988: 18-19), in fact, follow such a line in their account of the English progressive (asserting the superiority of such a theory to a possible worlds account). However, we think that such a move - mapping the causal function to the conceptual event - is missing an important fact about the world: there is already a fundamental concept in the relevant domain that is itself not result-entailing when ceteris non paribus, namely force, which can be thought of as a directed input of energy that may or may not provoke an effect, depending on the circumstances.

The key advantage of force and energy talk over event talk lies precisely in the ability of forces to interact with each other. It is natural to think of a force summing with another force to create a larger impetus to an end; similarly, it is natural to think of defeasibility as stemming from a case where a force counteracts another force that, without that intervention, would have led to some particular end. In contrast, it is not clear how one event might perturb or sum with another, especially if an event corresponds formally to the adjustment of a value on a scale. Neither is it altogether clear in what sense two events might help, oppose, prevent, or maintain one another. What is missing from event-talk is a clear notion of just how something external to the event can intervene to change the adjustment of the value along the scale; we certainly don't have a model of how values on various scales might interact with each other. An event-theorist might object that they are not in the business of modeling such interactions, which is fine, but we

\footnotetext{
${ }^{7}$ In this our proposal will end up having a similar flavor to Asher's (1992) and Glasbey's (1996) theories of the progressive; see also Engleberg (2002). Asher characterizes a 'perspective' as a "subset of information about a state." For Asher, the inference from $\operatorname{Prog}(\varphi)$ to $\varphi$ is defeasibly valid; it can, in particular, be defeated by the inclusion of additional information from the speaker's perspective. The difference between these theories and ours is that while theirs deal with information states, ours deals with states of affairs in the world. Inferences can be thought of as the informational analogue of forces. It also assumes determinism if the speaker has perfect knowledge.

${ }^{8}$ Davidson (1967) expresses skepticism that events can be represented by transitions from one state to another, remarking that there are any number of ways to go from San Francisco to Pittsburgh (by foot, by air, by mule, ...) and all these are different kinds of events although the initial and final state are the same. This objection does not, however, pertain to the idea of events as functions from one state (situation) to another. There are any number of ways to get from the integer 2 to the integer $4\left(x+2, x^{*} 2, x^{2}, \ldots\right)$ by way of distinct functions; likewise, there are in general different ways to get from one situation to another by way of distinct functions.

${ }^{9}$ In a related vein, the analytic tradition that includes Discourse Representation Theory and Dynamic Semantics (Kamp 1981, Heim 1982, Groenendijk and Stokhof 1991, Kamp and Reyle 1993, Beaver 2001, etc.) also formally implements causal transitions between information states.
} 
will argue that this ability to model interaction allows for a perspicuous approach to several thorny empirical problems. ${ }^{10}$

This ability of forces to model intervention is especially appropriate in the analysis of a long-standing puzzle in the event-structure literature concerning the status of verbs of maintaining like keep and stay (Jackendoff 1975, a.o). They are clearly dynamic, as diagnosed by the usual eventuality tests; for example, the progressive gets an 'ongoing-now' reading. ${ }^{11}$

(8) a. The rock is keeping the door open.

b. The door is staying open.

Their occurrence in the progressive shows that these verbs can be dynamic. However, the fact that they are interpreted habitually in sentences such as those in (9) with the simple present indicates that they must be dynamic:

(9) a. The rock keeps the door open.

b. The door stays open.

In an event-based framework, it is difficult to understand what distinguishes such dynamic eventualities from stage-level statives such as The door is open. In standard neo-Davidsonian approaches, both kinds of predicates take a Davidsonian argument, and both make reference to a situation in which the The door (is) open holds, so there is no obvious formal rationale for their distinct aktionsart types. Further, in a semantics in which the Davidsonian argument is an event and events are characterized by change (see Lombard 1979, Cleland 1991: 245 for philosophical perspectives on how to characterize events in this fashion), it is difficult to understand the notion of a "eventive" eventuality like keep or stay in which nothing changes.

In contrast, the discussion of such verbs in the cognitive linguistics literature (Talmy, 2000, e.g.) points out that the key difference betwen The door was open and The door stayed open has to do with the fact that the latter lexically encodes the presence of a force that intervenes to counteract the ceteris paribus result of an existing force; without the staying force, the door would not have remained open. The dynamic character of these predicates, we argue, reflects the fact that they involve a force, not that they involve an event or change of any kind.

To capture the notion of intervention that will allow us to account for cases of perturbation and maintenance, we will map conceptual forces to functions that have the form of the causal function described above in (7), with one small but important change: if we are to interpret the causal function we described above as an actual force - that is, as a token, rather than a type of force - it will necessarily have to have a single situation in its domain. So instead of a single broad causal function with many situations in their domains, we now have many

\footnotetext{
${ }^{10}$ It is interesting to note that facts (information, inferences) can interact in a defeasible fashion as well (Asher, 1992, and see footnote 8 above). However, if we work only with facts, we give up the advantages of Davidsonian modification. We think forces are a good compromise between the Davidsonian evidence that make us want to anchor our ontological entity in the physical world (i.e., what events are good at), and the ability of these entities to interact with each other, even to construct different possibilities that proceed from a present situation selected by the speaker (i.e., what facts are good at; and see Kratzer 2013, e.g. for an indication that mainstream modal theory is moving in that direction).

${ }^{11}$ Note that here we are using 'dynamic' to refer to predicates that in other literature are termed 'eventive', not in the more restricted sense employed in, e.g. Maienborn (2005) et seq. where 'dynamic' is reserved for the 'process' or 'happening' subclass of eventualities, those involving change. See discussion at the end of section 5.3 below for discussion of why we believe this is the correct place to make the type-theoretic cut.
} 
small causal functions, each with a single situation in their domain, and each meant to map to a force token.

Intervention is then easily modeled using such force functions: two functions operating on the same situation can be summed to yield a different result than the result that one would get just from one of the two functions. Moreover, the ability to represent intervention is just one of the properties that make the notion of force suitable for addressing the empirical challenges we lay out above. Forces are intuitively spatially and temporally located, in that they arise from objects and their properties, which are themselves the components of spatially- and temporallylocatable situations. Lastly, forces can transform objects and/or their properties - that is, they create new situations from old situations. For any given situation, we can sum the forces acting in it to arrive at a net force, whose ceteris paribus effect will be to lead to the subsequent situation. 'Ceteris paribus' now means exactly that no outside forces intervene, where 'outside forces' are those that arise at least partially from entities outside the situation under consideration.

\section{A selective tour of theories involving forces}

In this section we take a very brief tour of some relevant existing work. We note that many researchers working on verbal semantics have turned to concepts such as 'force' and 'energy' even when they have not explicitly used these intuitions in their theories, or, when they have, have not provided a formal interpretation of them. Psychologists investigating intuitions about causation have developed a consensus that causal reasoning is driven by the perception of physical causal mechanisms connecting entities; this finding implicates forces. Finally, we address the state of the art within formal linguistics, especially the only existing formal framework we know of to use the notion of forces (van Lambalgen \& Hamm 2003, 2005), and detail how our approach relates to it. This review serves to situate our proposal, developed in the following sections, that the causal function itself maps to a conceptual force in the mental representation of the world, and ultimately, that the causal function takes the place of the event argument for dynamic eventualities.

\subsection{Generalizing forces for verbal meanings}

One might wonder whether the notion of 'force' be generalized or abstracted in a useful way to all dynamic verbal meanings. We draw an analogy to a more familiar (at least to formal linguists) abstraction, one that abstracts away from physical motion to abstract motion, i.e., other kinds of change. This kind of abstraction is already present in Aristotle's Physics (V.2):

...there can be motion .. in respect of Quality, Quantity, and Place... Motion in respect of Quality let us call alteration.... Motion in respect of Quantity ... is called increase or decrease.... Motion in respect of Place ... we may designate ... by the general name of locomotion....

As we have noted above, this insight has been incorporated into modern event semantics via the concept of a scale. ${ }^{12}$ However, like physical motion, physical forces can be abstracted in the

\footnotetext{
${ }^{12}$ Aristotle does not extend this analysis to verbs of creation and destruction (V:1): "those which take the form of 'becoming' and 'perishing', that is to say those which imply a relation of contradiction, are not motions..." We
} 
same way. Indeed, the prototypical cases of physical forces are those that may (or may not) produce motion of an object: think billiard balls. It seems reasonable, therefore, for a model of physical forces to be generalized to other domains in a similar sense: representing inputs of energy that may or may not cause changes of an abstract kind.

In the cognitive linguistic tradition, forces have been generalized in this way to form the core of all dynamic verbal meanings. Talmy $(1976,1981,1985 a, b, 1988,2000)$ was the first to systematically apply the notion of force to meanings, starting from the common-sense insight that the meanings of certain expressions (e.g., keep, help, prevent, despite, etc.) are easily characterized in terms of force-dynamic interactions. Talmy's insight has been explored and developed at length by others. Croft $(1990,1991,1998$, e.g.) follows Talmy in treating active verbal predicates as denoting force-dynamic relations, and in understanding causation through this lens. In a prototypical causal scenario, for example, "one participant acts on another participant and transmits its force to the other participant, which then undergoes a change" (Croft 1998:83). Langacker (1991:118) expresses this same idea in his 'billiard-ball' model of causation. Gärdenfors (2007) similarly extends the Talmian project to characterize verbal concepts as patterns of forces:

Even though our cognition may not be built precisely for Newtonian mechanics, it appears that our brains have evolved the capacity for extracting the forces that lie behind different kinds of movements and action.... In accordance with this, I submit that the fundamental cognitive representation of an action consists of the pattern of forces that generates it. (Gärdenfors, 2007: 254)

The idea of a force is also represented in the formal literature as an intuition even where it has not been developed in a formal sense. Consider the following characterizations of intervention: "[W]e assume in reasoning ... that...other outside forces don't intervene." (Asher, 1992: 491); "Landman points out that sometimes the forces out to stop an event are just too strong to allow a progressive sentence to be true." (Portner, 1998: 766; Landman does not in fact use the word "force" in his 1992 article.) And of event structure: "The causal chain represented in an event structure is essentially a representation of the event as a series of force-dynamic relations." (Rappoport-Hovav \& Levin 2001: 787).

Similarly, the idea of energy, closely related to the idea of force, has long been understood to be fundamental to the relationship between states, events, and to transitions from one to another: ${ }^{13}$

"With a state, unless something happens to change that state, then the state will continue.... With a dynamic situation, on the other hand, the situation will only

\footnotetext{
assume, however, that it applies to all predicates; see our treatment of incremental theme verbs in section 4.2 below. This generalization to change along a scale is pervasive in the lexical semantic, cognitive linguistic and formal literatures on events (see, among very many others, Levin \& Rappoport Hovav 2008, Jackendoff 1975, 1991, Talmy 2000, Croft 1991, Ramchand 1997, 2008, Hay, Kennedy \& Levin 1999, Kennedy and McNally 2005, Kennedy and Levin 2008, etc.)

${ }^{13}$ In related discussion, Bohnemeyer and Swift (2006) recognize the importance of force in the semantics of the English progressive for certain predicates, though they characterize 'change' rather than energy or force as the defining property of dynamic predicates. Many others have also described dynamic predicates as crucially involving 'change', including Dowty 1979, Kearns 1991, and McClure 1994. We address the question of whether dynamic predicates always entail change in section 5.3 below, in our discussion of verbs of maintaining.
} 
continue if it is continually subject to a new input of energy. [...] To remain in a state requires no effort, whereas to remain in a dynamic situation does require effort, whether from inside or outside ." (Comrie 1976: 49)

"Events and states also differ in energeia, or dynamism. Events require energy... [s]tates consist of an undifferentiated period, and continue unless something happens to change them." (Smith 1997: 36)

The notions of force and energy, then, have been repeatedly implicated in the study of verbal meaning.

We turn now to psychological research on causation, which also suggests that the use of forces to account for verbal meaning is cognitively plausible. This suggestion stems from findings demonstrating the primacy of forces in causal reasoning, including when causal interactions are described linguistically using verbal predicates.

\subsection{Research on causation implicates physical causal connections}

There is a consensus in the psychological literature on causation that, as cognitive linguists would predict, people's representations of physical reality do include information about causation physically anchored in space and time, over and above basic spatio-temporal properties such as motion. Michotte (1946/1963) hypothesized the existence of a dedicated causal perception mechanism, based on the results of experiments manipulating the temporal and spatial distance between interacting objects in animated sequences. Subsequent work building on his results confirm the primacy of causal perception, in adults and also in infants. For example, Leslie and Keeble (1987), using a preferential looking paradigm, showed that infants as young as six months old perceive causation. Subjects were shown a sequence where a hand is moving together with an object, in two conditions, either where the hand contacts the object or where the hand does not contact the object. When the sequence was run backwards, the infants were habituated in the non-contact condition, but looked more in the contact condition. This suggests that the infants interpreted (only) the contact condition as a causal event, which would seem quite different if run backwards in time. ${ }^{14}$ Walsh \& Sloman (2011) present experimental evidence that adults tend to attribute causation only when there is the possibility of a physical causal mechanism between two events; in the absence of such a possibility, causation is attributed much less, even when there is a correlation between the two events. This result strongly suggests that in people's mental representation of a scene, they have access to the notion of a physical causal mechanism. Indeed, work by Wolff and others (Wolff \& Song, 2003, Wolff 2007, Barbey and Wolff 2007, Wolff, Barbey, \& Hausknecht, 2010, Wolff, Hausknecht, \& Holmes, 2011, Wolff, in press) has extensively argued for the psychological validity of these proposals using experimental methods. These experiments show that the magnitudes and interaction of physical forces in a virtual environment can be very precisely predictive of speakers' choice of lexical items for causal predicates, and that the effects transfer unproblematically to psychosocial contexts.

Force dynamics allow us to model causal information as physically anchored in space

\footnotetext{
${ }^{14}$ See also Saxe \& Carey (2006) for an overview of research on infants' representations of causation. This research tends to elaborate on the kind of causal knowledge that infants have, rather than objecting to the idea that infants have causal knowledge.
} 
and time. In fact, to the extent that causal information is always thusly anchored, force dynamics may be the best way to model causal information, since spatio-temporal information is crucial to forces, but not to other theories of causation. Copley \& Wolff (in press) argue that the fact that spatio-temporal information is relevant to causal attribution indicates that a production/mechanistic theory such as force dynamics should be used to explain mental representations of causation, since alternative theories that represent causation in terms of dependencies (counterfactual, probabilistic, e.g.) do not in and of themselves anchor causal relations in time, but generally have to add a separate temporal variable.

Although the relevance of forces for models of causation is coming to be recognized in the psychological literature, investigation of the relationship between cognizing about forces and cognizing about causation is ongoing. White (2011), for instance, concludes that forces and causation are independent of each other, based on experimental results showing that subjects' impression of force magnitude in animated sequences is influenced by the size of a gap between two interacting objects, as well as by the presence of an intervening third object, but their impression of causation is not. ${ }^{15}$

\subsection{Forces in formal linguistics}

Despite the ubiquity of the concept of 'force' in cognitive linguistics, and its usefulness in psychological investigations of causation, as far as we know, there have not been many formal linguists who have explicitly deployed the concept of force in the analysis of natural language phenomena. Those who have, have not gotten as far as providing a formal interpretation (we have in mind Vecchiato 2003, 2004 and Zwarts 2010).

The only formal semantic framework to systematically employ the concept of 'force' that we are aware of is work by van Lambalgen and Hamm (2003, 2005). The latter authors share several convictions with the present approach. One such shared conviction is that the concept of ceteris paribus - their notion of 'inertia' - is central to the treatment of verbal predicates, is ultimately derived from representations of causation, and should be treated directly in the model: possibilities are derived from causation, instead of the other way around as Lewis (1973) proposes. Another shared idea between the present approach and van Lambalgen and Hamm is that there is a kind of local determinism such that there is always a single "next thing" that happens:

"We interpret fluents as sets of intervals of the form $[0, b]$ or $(a, b]$, where $a$ is the instant at which an initiating event occurs, and b is the instant where 'the next' terminating event occurs. Talk about 'the next' seems justified due to the inertia inherent in fluents." (van Lambalgen and Hamm 2005: 47)

\footnotetext{
15 There are two reasons why White's results do not derail the current project. One is that it is perfectly
} possible for there to be forces acting without the source of those forces being a subject of the main verb cause (used in White's instructions to subjects). The second is that, following ongoing debate in the philosophy of causation, we are happy to remain agnostic on the question of whether a single theory of causation can account for all causal impressions (Anscombe, 1971; Hall, 2004; Copley \& Wolff, in press, and especially Godfrey-Smith, 2009 for an overview of the topic). Copley \& Wolff, in press, suggest that spatio-temporal anchoring may be most relevant in the verb phrase, but less relevant outside it. In this paper we remain inside for the most part the verb phrase, but leave open the possibility that other notions of causation operate outside of it. 
This same assumption underlies our contention (above) that it is appropriate to represent causation as a function, with a unique output.

However, it is important to note some differences between our proposal and van Lambalgen and Hamm's as well. One basic ontological distinction in van Lambalgen and Hamm's model is a temporal distinction, between instantaneous events and time-dependent (noninstantaneous) fluents. A fluent can either be a state such as "have momentum $m$ " or a force that continuously causes another fluent. The ontology of their system groups states and continuous forces together, but does not identify dynamic eventualities as a natural class distinct from states, which is needed to account for the adverbial data from Katz that we discuss below in section 5.1. A more conceptual point is that while van Lambalgen and Hamm are of the opinion that it does make sense to talk about events "intervening" to change properties, we feel, as we have said above, that in the absence of a mechanism which can explain how an event (understood as a 'change') can itself initiate 'change', event-talk does not further our understanding of intervention in the same way that forces can. Thus we do not adopt van Lambalgen and Hamm's model.

We should also point out that, in contrast to both the cognitive tradition and van Lambalgen and Hamm's work, we seek to elucidate how the representation of force in the semantics interfaces with the syntax, taking into account recent models of the syntax-semantics interface. With a view towards this goal, we implement the notion of force in the next section.

\section{A scaffolding for a force-theoretic semantics}

Overall, despite the longstanding interest in, and inherent plausibility of, the idea of force, the difficulty of expressing force in current model-theoretic approaches has inhibited further development of this idea at the syntax-semantics interface. More than one researcher has expressed their interest, however, in a formalized theory of forces that would integrate naturally with what we have learned about the syntax-semantics interface (see, e.g., Dowty, 1991: 575, Rappaport Hovav \& Levin 2001:785 n. 21, Beavers 2011: 357). We provide a sketch of such a theory here; for a full model-theoretic treatment, and more detailed discussion of the philosophical and conceptual underpinnings, see Copley \& Harley, in preparation. For the brief presentation here, we will concentrate on force functions and situations, but a few words must be said first about the mapping between conceptual forces and (conceptual) situations on the one hand, and force functions and situations on the other.

\subsection{Forces and situations}

A conceptual force $\varphi-$ a force as it is perceived and mentally represented - is an input of energy that arises from individuals and property attributions (or tropes) in an initial conceptual situation $\sigma$. A situation may have many such forces, indeed even a pattern of forces in the sense of Gärdenfors 2007. For simple spatiotemporal forces we can think of the representation as similar to a free-body diagram with one or a number of vectors, but such representations can be extended to more abstract cases - one of the central precepts of cognitive linguistic analysis.

The force summation calculation for a situation may be abstracted in a way that is massively multidimensional, including forces acting in directions other than the purely spatial. In our model, forces (inputs of energy) are what produce change. As noted above, we therefore conclude that forces are appropriate to model predicates denoting any type of change, not only change of location. Thus forces can arise that produce any of the kinds of changes that Aristotle alludes to: a 'grow' force (an input of energy that ceteris paribus provokes an increase in size), a 
'redden' force (an input of energy that ceteris paribus provokes a change in color qualia), a 'straighten' force (an input of energy that ceteris paribus provokes a change in linear configuration), etc. In this way, we generalize from forces with purely spatiotemporal effects to those with all kinds of other effects.

We assume, then, that the cognitive system calculates the trajectory or development of that situation as a whole; Zacks et al. (2011) show, by observing behavior and brain activity during near-future prediction tasks, that prediction of the development of a situation is psychologically real and is sensitive to transitions. This calculation may occur either by means of a truly force-based simulation or in a more abstract sense, recognizing that both modes may be interleaved (Hegarty 2004, e.g.). We refer to this calculation as 'force summation', recognizing that it takes into account the predicted consequences of all the forces represented in $\sigma$, not just those acting on a single entity.

The result of the summation is a force which produces the single situation $\sigma$ ' that happens next. We will call this force the '(conceptual) net force' of the initial conceptual situation. The estimated outcome of the predicted trajectory is itself a situation, which may or may not differ from the initial situation; this is the mapping from situations to situations that corresponds to our formal treatment of force as a function. ${ }^{16}$

A conceptual net force $\varphi$ is mapped to a (linguistic) force function $\mathrm{f}$. Force functions are functions from linguistic situations to linguistic situations, where a linguistic situation $\mathrm{s}$ is a representation at the linguistic level of a conceptual situation $\sigma$ on the conceptual level. A force function maps an initial linguistic situation to the linguistic situation that (represents the conceptual situation that) occurs if nothing external intervenes, i.e. the situation that occurs ceteris paribus. Note that our formal force function differs from the conceptual forces detailed in Croft, 1990, 1991 and other cognitive linguistic approaches, in that force functions act on entire situations rather than acting on a particular object (the 'force recipient').

We can summarize our conception of situations and force functions in language as in (10) and (11) below:

\section{(Linguistic) situations:}

A (linguistic) situation s corresponds to a conceptual situation $\sigma$, which is a spatiotemporally bounded "annotated snapshot" of individuals and their property attributions.

We stress that situations of both kinds in this sense can be possibilia: they may exist in a set of possible situations without necessarily occurring. We mean for (10) to be in line with interpretations of situation semantics/DRT approaches in which situations/DRSs are representations of mental models. We construct representations of conceptual forces within the mental model of the state of affairs, by relating a conceptual situation $\sigma$ to a conceptual force $\varphi$,

\footnotetext{
${ }^{16}$ Note that some forces are produced not by the behavior or motion of particular entities or objects, but are the result of the application of natural laws and generalizations, for example, the interaction of objects with mass and a gravitational field. Forces associated with gravity have been shown to be relevant to mental representations, especially in linguistic contexts (Freyd et al. 1988; Holmes \& Wolff 2010, 2013). We consider the collected set of natural laws and generalizations to be the 'normal field': the propensity of certain individuals and properties to generate forces in particular circumstances unless prevented from doing so. An object with mass in a normal gravitational field will have weight and fall unless prevented from doing so; similarly, an object (e.g. foodstuffs) with organic material in a normal temperate climate will have rotting potential and degrade, unless prevented from doing so, etc.
} 
as in (11) below. This conceptual force $\varphi$ is mapped to a force function:

(11) (Linguistic) force functions:

A (linguistic) force function $\mathrm{f}$ is a function from an initial (linguistic) situation $\mathrm{s}$ to the (ceteris paribus, linguistic) final situation s', which corresponds to a conceptual net force $\varphi$. The latter is a (mental representation of) an input of energy that arises from all the individuals and their property attributions in a conceptual situation $\sigma$.

To represent situations in a Montagovian semantics (Montague 1970), we assign them the primitive type $\mathrm{s}$.

$$
\begin{aligned}
& \text { Type of situations: } s \\
& \text { Type of forces: }<s, s>
\end{aligned}
$$

As we have said above, we propose to represent forces as functions from situations to situations. The idea behind the $<\mathrm{s}, \mathrm{s}>$ type is again an assumption that we share with van Lambalgen and Hamm, that there is such a thing as the next situation (see also Kamp 1979, Bittner 1999 for an event-based version of this point). That is, if you have an initial situation and a force is applied, and no stronger force intervenes, the final situation results - not a different set of situations but a single situation, since a single physical force can only lead from a situation to another, possibly similar situation, and never to a set of situations. This means that the only functions of type $<\mathrm{s}, \mathrm{s}>$ that can be mapped to conceptual forces in our system are those with a single situation in their domain and a single situation in their range. For convenience we will abbreviate type $<\mathrm{s}, \mathrm{s}>$ as type $\mathrm{f}$.

Because conceptual forces arise from individuals and their properties in conceptual situations, we can relate forces to situations, not only on the conceptual level, but on the linguistic level as well. When a force arises from all the individuals and properties in a situation, it is the net force of the situation. The net force, as discussed above, yields a unique output situation. Since we assume local determinism, we may speak of causal chains of situations or forces, with the net force of one situation, when applied to that situation, resulting in a unique successor situation. The diagram below depicts a causal chain made up of situations (the vectors are depicted in the bubbles because the conceptual forces arise from the conceptual situations represented by the bubbles).

(13) Causal chain of situations with net forces

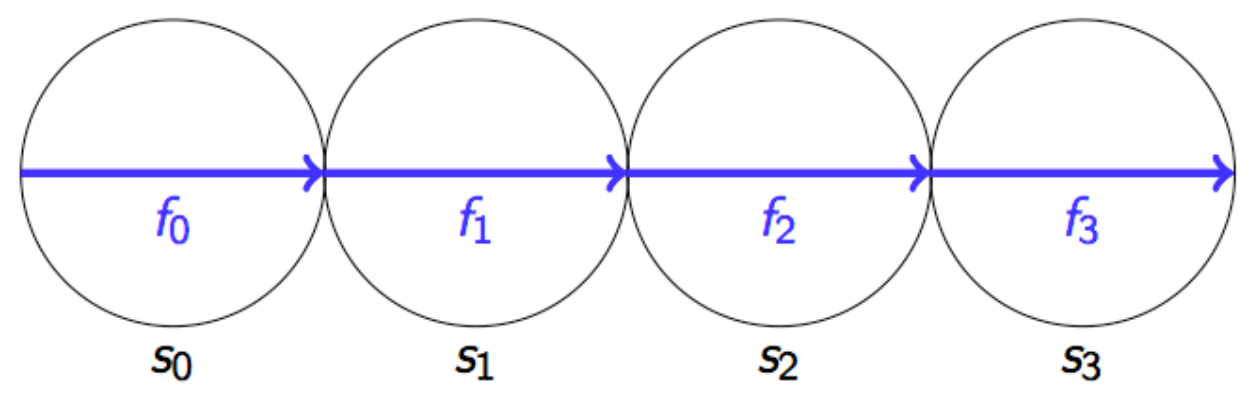


We assume that for a given linguistic situation $s_{n}$, we can always recover its net force $f_{n}$.

$$
\text { net(s) }=: \text { the net force of } s
$$

By means of the inverse of the function $n e t$, net ${ }^{-1}$, we can define two other functions that will be useful when we refer to forces and situations in denotations, as we will see below in sections 4 and 5. Given a (particular, spatiotemporally bounded) force f, we can refer to both the situation of which it is a net force, and the situation that follows. The initial situation of $\mathrm{f}$ is simply the situation $\mathrm{s}$ of which it is a net force. The final situation is the situation that results when $\mathrm{f}$ takes $\mathrm{s}$ as its argument. ${ }^{17}$ The functions init and fin are defined with respect to the inverse function of net. $^{18}$
a. $\operatorname{init}(f)=\operatorname{net}^{-1}(f)$
b. $\operatorname{fin}(f)=f\left(\operatorname{net}^{-1}(f)\right)$

We define as well a situation's successor and predecessor situation:
a. $\operatorname{suc}(s)=\operatorname{fin}(\operatorname{net}(s))$
b. $\operatorname{pred}(\mathrm{s})=\operatorname{suc}^{-1}(\mathrm{~s})$

As usual, individuals will be represented by variables $\mathrm{x}, \mathrm{y}, \mathrm{z} .$. and will have type e. Predicates are represented by lowercase Roman letters p, q, etc. When they are (stage-level) statives, they are predicates of situations, type $<\mathrm{s}, \mathrm{t}>$, and when they are dynamic, they are predicates of forces, type $<$ f,t $>$.

When an individual's property has a leading role in generating a conceptual force, we will say that the individual is the source of the corresponding linguistic force. We discuss the notion of 'source' in further detail in section 4.5 below, although without coming to an exhaustive definition of "leading role". In any case, the 'source' relation will serve the same purpose in our denotations as 'agent' or 'causer' serves in event-based frameworks.

\subsection{Efficacy and the ceteris non paribus cases}

We argued above that the notion of intervention seems to be key to understanding the ceteris non paribus cases. Built into this notion is a distinction between internal (or judged relevant) circumstances and external (or unexpectedly relevant) circumstances; an intervention is an interaction where a force arising at least partially from external entities and/or properties interacts with internal forces. This distinction can be modeled quite easily by exploiting the speaker's judgment as to which entities and properties go into the initial situation. Not incidentally, the categorization of entities and properties as internal or external to the initial situation will also be crucial to reconciling our assumption of local determinism with branching possibilities.

\footnotetext{
${ }^{17}$ As noted by a reviewer, the job done by fin(f) could equally be described in terms of the init function, as fin $\left(\mathrm{f}_{0}\right)=$ $\operatorname{init}\left(\mathrm{f}_{1}\right)$; we could thus define a single function that takes forces and returns situations, instead of two such functions as in (23). However, we retain the distinct names for their intuitive ease when relating with the initial and final situations of a force to a lexical entry; cf. the 'beg(e)' and 'end(e)' functions in Kennedy (in press).

${ }^{18}$ For any function $\mathrm{F}$ whose domain is over $\mathrm{x}$ and range is over $\mathrm{y}$, a function $\mathrm{G}$ is the inverse function of $\mathrm{F}$ (written as $\mathrm{F}^{-1}$ ) iff for all $\mathrm{x}, \mathrm{G}(\mathrm{F}(\mathrm{x}))=\mathrm{x}$, or equivalently, $\mathrm{F}(\mathrm{x})=\mathrm{y}$ and $\mathrm{G}(\mathrm{y})=\mathrm{x}$.
} 
We begin with a definition: a situation $\mathrm{s}_{0}$ is efficacious just in case its ceteris paribus successor situation occurs. Consider the diagram in (17) below. When choosing an initial situation $\mathrm{s}_{0}$, the speaker chooses (the) one that she judges to be efficacious. For example, she may judge that $\mathrm{s}_{0}^{\mathrm{a}}$ is the efficacious situation; in that case, given her conception of the contents of that situation, she is judging that no forces arising at least partially from outside $\mathrm{s}_{0}^{\mathrm{a}}$ will perturb $\mathrm{f}^{\mathrm{a}}{ }_{0}$, so that $\mathrm{s}_{1}^{\mathrm{a}}$ will indeed occur. Of course, something from outside $\mathrm{s}_{0}{ }_{0}$ may well intervene, in which case perhaps the efficacious initial situation is $\mathrm{s}_{0}^{\mathrm{b}}$ and what will occur is its successor $\mathrm{s}^{\mathrm{b}}{ }_{1}$. So while there is local determinism, what eventually happens is not determined by the situation the speaker picks. This diagram exemplifies how the force-theoretic framework deals with non-determinism; the causal chains picked out by superscripts a and b correspond rather well to "histories," as in Thomason 1970.

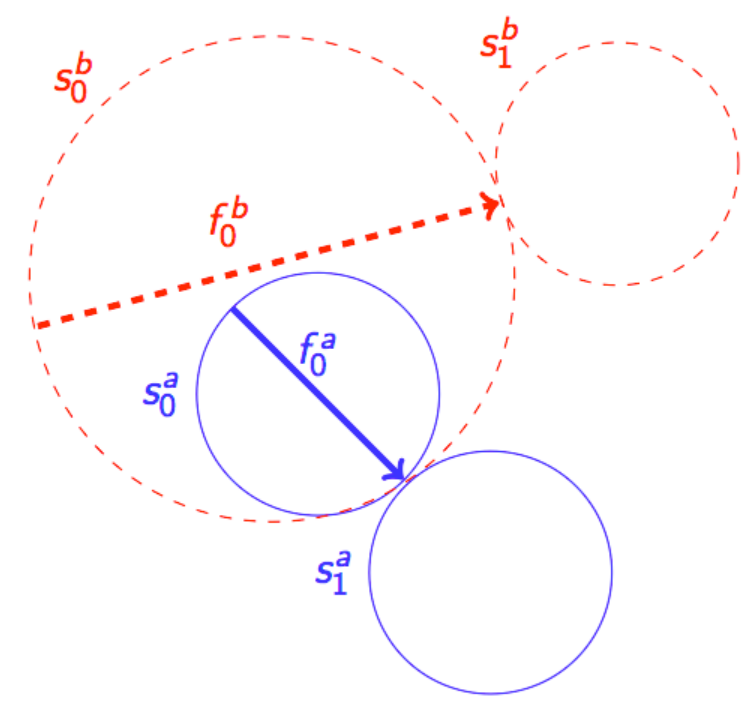

The notion of efficacy will allow us to further understand our ceteris non paribus cases, that is, the non-culminating accomplishments and the English progressive.

We propose that the difference between forms that entail culmination of accomplishments (that is, entail that $\mathrm{s}_{1}$ comes about, as in an English perfective) and forms that do not (like the Tagalog neutral form) is that the former presuppose that the initial situation is efficacious, while the latter have no such presupposition. ${ }^{19}$ As we mentioned above, this makes the non-culminating forms illustrated in (2-5) above more basic than the forms that entail culmination, contra inertia world treatments of non-culminating accomplishments such as Koenig and Muansuwan, 2001, Matthewson, 2004, and Tatevosov, 2008, and this is consistent with their comparatively unmarked morphological structure.

The meaning of the English progressive in (1) is different from that of non-culminating accomplishments. We assume that Aspect maps from predicates of forces to predicates of

\footnotetext{
${ }^{19}$ In fact, we have proposed elsewhere that there are forms which presuppose that the initial situation is not efficacious: 'frustratives' in Tohono O'odham (Copley \& Harley, in press). Futures and futurates also seem to have a presupposition related to the success of the eventuality (Copley, 2002, 2008, 2009). In the cases at hand, not all of the presupposition tests give clear results to decide whether efficacy is part of the assertion or a presupposition. However, in these other cases the analogue of efficacy (or non-efficacy, in the case of frustratives) is more clearly a presupposition, in that it survives questioning, negation, etc. So on balance, we think that also in the cases discussed here, efficacy is probably a presupposition.
} 
situations, so it is type $<<\mathrm{f}, \mathrm{t}>,<\mathrm{s}, \mathrm{t}>>$ (this assumption is analogous to the common assumption that aspect maps from event predicates to temporal predicates; Klein 1994, Kratzer 1998). As a proposal, we suggest a denotation for progressive sentences that takes a predicate of forces $(\pi$, the denotation of the $v \mathrm{P})$, and a situation ( $\mathrm{s}_{0}$, the situation provided by tense), and says that, according to the speaker, $\pi$ holds of the net force of $s_{0}$.

$$
\llbracket \text { progressive } \rrbracket=\lambda \pi \lambda \mathrm{s} . \pi(\operatorname{net}(\mathrm{s}))
$$

The efficacy entailment that is otherwise apparent in perfective sentences seems to disappear in the progressive. The question, then, is whether this presupposition is somehow cancelled in these progressive sentences, or whether, perhaps, it actually arises from perfective or some other aspect (as in Singh 1998, Altshuler 2013, e.g.) rather than in the vP, so that the presupposition doesn't arise at all in the case of the progressive. We set investigation of these and other options aside for the purposes of this paper.

This concludes our brief sketch of what a force-theoretic semantic model should, at minimum, include. In the remainder of the paper we will investigate how this force-theoretic framework can be implemented at the syntax-semantics interface, given a specific set of assumptions about the structure of the relevant syntactic representations. The logical forms (i.e., meanings) we propose could easily be recast in an alternative representation of lexical-semantic structure, even if one does not wish to make the specific assumptions we make about the syntax (or indeed any assumptions at all about the syntax). However, we feel strongly that the use of syntactic evidence to constrain and inform theories of meaning enhances the relevance of both semantic and syntactic theorizing.

We will first consider how force-theoretic representations integrate with syntactic argument structure, and subsequently, in section 5, we will show how this integration accounts for distinctions between dynamic and stative predicates.

\section{Argument structure and event structure}

We now turn to the integration of the force-theoretic framework with one current understanding of verbal argument and event structure, focusing on the representation of different eventuality types and their argument-structural properties. We will first consider how the various subclasses of dynamic predicates are composed, beginning with changes of state. Recall that we have proposed that the foundational distinction between stative and dynamic predicates is that stative predicates are predicates of situations, type $<\mathrm{s}, \mathrm{t}\rangle$, while dynamic predicates are predicates of forces, type $<f, t>$.

\subsection{Changes of state}

The recent explosion of work on the argument structure/event structure interface has resulted in the development of a broadly accepted syntactic decomposition of the VP, into two or more phrasal projections, the maximal one typically labelled 'vP'. We adopt several core assumptions of the general approach in our proposal below, mostly those which have to do with the view that the internal structure of vP is generally isomorphic with the internal structure of events. However, any analysis which approaches subeventual structure in terms of hierarchically structured lexical-conceptual representations will easily be able to interpret our proposed 
recasting of the key components in force-theoretic terms. For change-of-state predicates in particular, we assume that each of the various subpredicates involved project independently in the syntax, and compose to generate the vP's denotation (Van Valin 1990, Hale \& Keyser 1993, Marantz 1997, Borer 1998, 2005, Kratzer 1996, Ramchand 2008, among many others). For the most part, the syntactic literature treats change-of-state predicates like melt as having (at least) two components: a causing event and a result state (though cf. Piñon 1997 and Marin and McNally 2011, where it is argued that some inchoative predicates are truly instantaneous). In the current proposal, the causing event corresponds to a force which is applied to a situation of which the resulting stative predicate does not hold. This force, ceteris paribus, yields a situation where the resulting stative predicate does hold, following Dowty (1979).

Since each subcomponent of a change-of-state predicate is introduced in a separate syntactic projection, a change-of-state-denoting vP minimally contains two phrasal projections. ${ }^{20}$ The lower portion of such a complex vP is taken to denote the resulting stative predicate. We assume it has the syntax of a small clause (SC) (see, among others, Hoekstra and Mulder 1990, Harley 2005, Ramchand 2008), which denotes a predicate $\mathrm{p}$ of situations (type $<\mathrm{s}, \mathrm{t}>$ ). The head of the upper portion of the complex vP, $\mathrm{v}^{\circ}$, thus takes a predicate of situations $\mathrm{p}$ as its argument and ensures that the vP node denotes a predicate of forces (type $<\mathrm{f}, \mathrm{t}>$ ). The $\mathrm{v}^{\circ}$ head introduces a force $f$ and asserts that $p$ holds of the final situation of that force - that is, it identifies fin(f) as a $p$ situation. The $\mathrm{v}^{\circ}$ head of a change of state predicate further imposes the requirement that that the initial situation of the force is a $\sim p$ situation. ${ }^{21}$ (Recall that by the definition in (15a) init $(f)=s$ if and only if net(s)=f, so the initial situation of $\mathrm{f}$ is the situation of which $\mathrm{f}$ is the net force.)

An inchoative sentence such as The door opened, for example, will contain a BECOME $\mathrm{v}^{\circ}$ head with the denotation below. In a language like English where sentences with telic predicates systematically entail completion, we propose that $\mathrm{v}$ introduces the presupposition that init(f) is efficacious; that is, that fin(f) occurs, as in (19).

$$
\begin{aligned}
& \llbracket \mathrm{v}_{\mathrm{BECOME}} \rrbracket=\lambda \mathrm{p} \lambda \mathrm{f} \cdot \mathrm{p}(\mathrm{fin}(\mathrm{f})) \\
& \text { presupposed: } \sim \mathrm{p}(\operatorname{init}(\mathrm{f})), \text { init(f) is efficacious }
\end{aligned}
$$

The structure of the vP in this case is as in (20); the highest node is a predicate of forces which is destined to be taken as an argument by aspect. Recall that aspect is itself of type $<<\mathrm{f}, \mathrm{t}>,<\mathrm{s}$, $\mathrm{t}>>$, so the combination of aspect with (20) yields a node at AspP (not shown) that denotes a predicate of situations, type $<$ s, $\mathrm{t}>$ (i.e., a proposition).

\footnotetext{
${ }^{20}$ One perspective on the historical development of theories about the syntax/event-structure relationship can be found in Rosen (1999) as well as in many of the references cited above.

${ }^{21} \mathrm{We}$ are here abstracting away from the fact that most such small clauses are headed by scalar predicates which denote relations between degrees, individuals and situations; see Hay, Kennedy \& Levin (1999), Kennedy \& McNally (2005), Kennedy \& Levin (2008), Levin \& Rappaport Hovav (2010), a.o. Nothing relevant to the discussion here hinges on the adaptations necessary to fully represent the scalarity of the embedded predicate; however, such machinery is certainly necessary to capture (at least) the interpretation of open-scale degreeachievement changes of state such as warm, cool for which a binary $\mathrm{p} / \sim \mathrm{p}$ opposition is intuitively problematic. Bobaljik (2012) shows that deadjectival verbs of this class always behave morphologically as if a comparison of degrees is involved, and argues for an embedded comparative element within the vP. In such cases we assume that the small clause predicate includes this element; $\sim \mathrm{p}$ is ' $\mathrm{x}$ does not have property $\mathrm{q}$ to a degree greater than $\mathrm{d}$ in $\mathrm{s}_{0}$ ' and $\mathrm{p}$ is ' $\mathrm{x}$ has property $\mathrm{q}$ to a degree greater than $\mathrm{d}$ in $\mathrm{s}_{1}$ ', where $\mathrm{q}$ is the property denoted by the embedded predicate. See also Kennedy (in press) and Copley \& Harley (2014) for related discussion.
} 


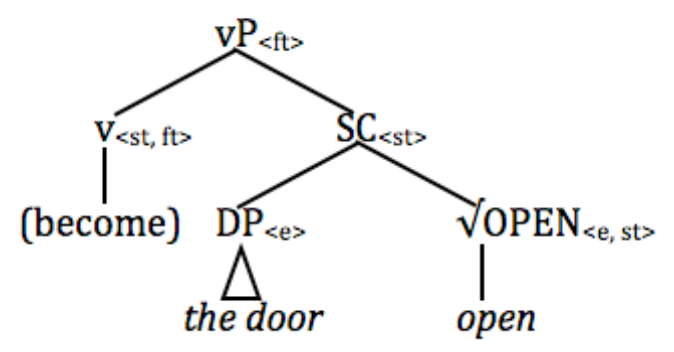

In the transitive alternant (John opened the door), we assume that the external argument is introduced by a Voice head, as argued by Kratzer 1996, Pylkkänen 2002, Cuervo 2003, Harley $2012 \mathrm{a}$, among many others. This head takes a predicate of forces as its complement and returns a function from individuals to a predicate of forces; it then composes with the external argument and returns a predicate of forces which asserts that said individual is the source of the force, whether by virtue of its inherent properties or (if animate) its intention to act.

$$
\llbracket \text { Voice }_{\text {ACTIVE }} \rrbracket=\lambda \pi \lambda x \lambda f . \pi(f) \& \operatorname{source}(x, f)
$$

The structural representation of the relevant portion of the transitive alternant (below AspP and $\mathrm{TP})$ is below:

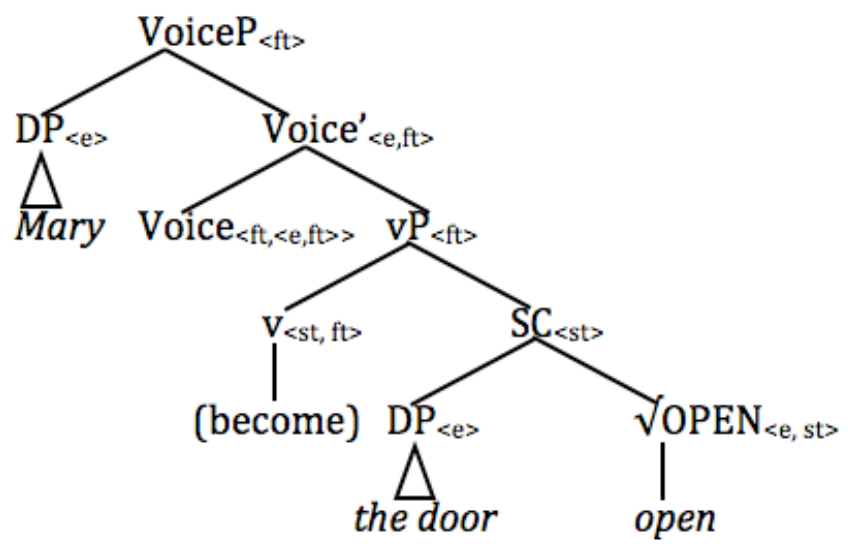

Examining the types associated with each node in the trees in (20) and (22) above, we note that no special composition operation need be invoked to bring together the different parts of the complex vP (compare, e.g., the rule of Event Identification introduced by Kratzer (1996) and widely deployed elsewhere).

Note that the vP and VoiceP in these change of state predicates has the type $<\mathrm{f}, \mathrm{t}>$, which is the type of a predicate of forces, that is, a dynamic predicate. We assume that what aspect applied to dynamic predicates does is to take a predicate of forces (VoiceP) and relate it to a (reference) situation, so that the resulting AspP projection has the type $<\mathrm{s}, \mathrm{t}>$. This is analogous to the familiar event-theoretic idea (e.g., Klein, 1994, Kratzer, 1998) that aspect takes predicates of events and relates them to times, though we leave open the question of how, or indeed whether, times are introduced higher in the structure. Projections higher than AspP also have the type $<\mathrm{s}, \mathrm{t}>$, with Tense relating the situation introduced by Aspect to the situation of utterance.

This hypothesis about the relationship of Aspect to predicates of forces provides us with 
our implementation of the standard observation that certain adverbials produce ambiguity in combination with change of state predicates. In the analysis here, sentences containing such predicates will contain at least two maximal projections of type $<\mathrm{s}, \mathrm{t}>$ : the small clause denoting the result state (the predicate of fin(f)), and the AspP that is the result of composing Aspect with the predicate of forces. Adverbials which compose with predicates of situations, then, will be able to modify either of these projections, and two interpretations will result. Standard cases are again adverbials and for $X$ time adverbials, which both compose with predicates of situations:

(24) Mary put the cup on the table again.

a. restitutive: It was on the table, then off it, then Mary put it on the table again.

b. repetitive: Mary had put it on the table before. She did the same thing again.

(25) Mary put the cup on the table for two minutes.

a. low reading: The cup was on the table for two minutes.

b. high: Mary put the cup on the table several times in the space of two minutes.

We assume that adverbials such as for two minutes compose via Predicate Modification, though nothing particularly hinges on this choice.

$$
\begin{array}{ll}
\text { a. } & \text { 【again } \rrbracket=\lambda \mathrm{p} \lambda \mathrm{s} \cdot \mathrm{p}(\mathrm{s}) \\
& \text { presupposed: } \exists \mathrm{s}^{\prime}>\operatorname{pred}(\mathrm{s}): \mathrm{p}\left(\mathrm{s}^{\prime}\right) \\
\text { b. } & \llbracket \text { for two minutes } \rrbracket=\lambda \mathrm{s} . \operatorname{dur}(\tau(\mathrm{s}))=\text { two minutes }
\end{array}
$$

Given these denotations, these predicates will adjoin freely to the embedded small clause predicate of situations in (20) and (22) above to yield the low reading. Similarly, they will adjoin to the higher AspP, following the composition of aspect with VoiceP, to yield the high reading.

A brief note on the derivation of surface form from these abstract syntactic structures: We adopt a 'realizational' view of the traditional Y-model of syntactic derivation, essentially that of Distributed Morphology (Halle and Marantz 1993), according to which phonological content is inserted into terminal nodes of the morphosyntax on the phonological branch of the derivation. Syntactic operations apply to transform the base-generated structures that are subject to interpretation illustrated here; for example, the $\sqrt{ }$ ('Root') node in (22) above undergoes headmovement to $\mathrm{v}$, and the resulting complex $\mathrm{X}^{\circ}$ constituent $\left[\sqrt{ } \mathrm{v}^{\circ}\right]_{\mathrm{v}^{\circ}}$ is realized as the verb open. (In some languages, the $\mathrm{v}^{\circ}$ node receives an overt morphological instantiation, as it does, perhaps, in English forms like clar-ify.) In other cases, as in (33) below, the root is combined with $\mathrm{v}^{\circ}$ via $\mathrm{m}$ merger, rather than head-movement, via what we might call the Matushansky gambit

(Matushansky, 2006). See Marantz 1984, Bobaljik 1994 for earlier applications of this idea, and Folli and Harley 2013 for an application to manner of motion predicates. See Harley (2012b) for a recent overview of the implications of a Distributed Morphology view of surface realization for semantic analysis.

With our approach to change of state predicates in place, we can turn to an analysis of other predicate types. 


\subsection{Coming into and going out of existence}

Change of state accomplishments are not the canonical accomplishment predicate. The cases which have been the subject of the most investigation (Verkuyl 1972, Krifka, 1989 et seq.) are accomplishments with an 'incremental theme' as an internal argument, as with the creation verbs below:

$$
\begin{aligned}
& \text { a. } \quad \text { Mary made a painting. } \\
& \text { b. } \quad \text { Mary made music. }
\end{aligned}
$$

In these cases, the direct object comes into (or, in the case of verbs of destruction or consumption, goes out of) existence, and it is the complete existence (or non-existence) of the object which determines the endpoint of the transition. In the current framework, one possibility we might consider is to treat these cases as involving a predicate of forces where the final situation is one in which an existence predicate holds. If we include this null existence predicate in the syntactic structure, as the predicate of a small clause as in $(20,22)$ above, however, we would predict a low-scope reading for the sentence in (28a) where for two hours would take the temporal trace of the existence of the painting as its argument; compare (28b) to (25a):

(28) a. Mary made a painting for two hours.

b. A painting existed for two hours.

There is no reading for (28a) in which a painting exists for two hours. The only reading available is the high reading, where for two hours adjoins to the AspP. We take this to indicate that there is no lower node of type $<\mathrm{s}, \mathrm{t}>$ to which the adverbial phrase for two hours can adjoin.

The assertion of the existence of an incremental theme, or its non-existence in the case of destruction/consumption verbs, must therefore be semantically, rather than syntactically introduced. These verbs must then be predicates of a force which has the effect that an individual which did not appear in the initial situation exists in the final situation. We have said before that situations are composed of individuals and their properties; we now characterize this relationship between situations and individuals for the grammar as a part-of relation $<$. We will say that $\mathrm{x}<\mathrm{s}$ holds if and only if the individual corresponding to $\mathrm{x}$ is in the conceptual situation corresponding to $\mathrm{s}$.

An incremental theme, then, will be the complement of a $v$ head which takes an individual and a predicate of forces whose initial situation is one in which the individual does not exist and whose final situation is one where it does. Note that we are still assuming that the external argument is introduced by the Voice head above, asserting that some individual is the source of the force; the $\mathrm{v}$ head itself merely asserts that an individual comes into existence. We therefore gloss it as 'appear', rather than 'make'. The denotation of this $\mathrm{v}$ head is given in (29) below. It ensures that the entity corresponding to $\mathrm{x}$ is not in the initial situation of the force, and is in the final situation of the force. As before, in English there is an efficacy presupposition associated with the $\mathrm{v}$ head.

$$
\llbracket \mathrm{v}_{\text {APPEAR }} \rrbracket=\lambda \mathrm{x} \lambda \mathrm{f} .[\mathrm{x}<\mathrm{fin}(\mathrm{f})]
$$

presupposed: $\sim[\mathrm{x}<\operatorname{init}(\mathrm{f})]$, init(f) is efficacious

The structure of the VoiceP in a sentence like that in (27a) or (28a) above, then, is illustrated in 
(30) (the full sentence would have at least an AspP and TenseP projection above VoiceP, contributing the content that ensures that the verb make is ultimately realized as made):

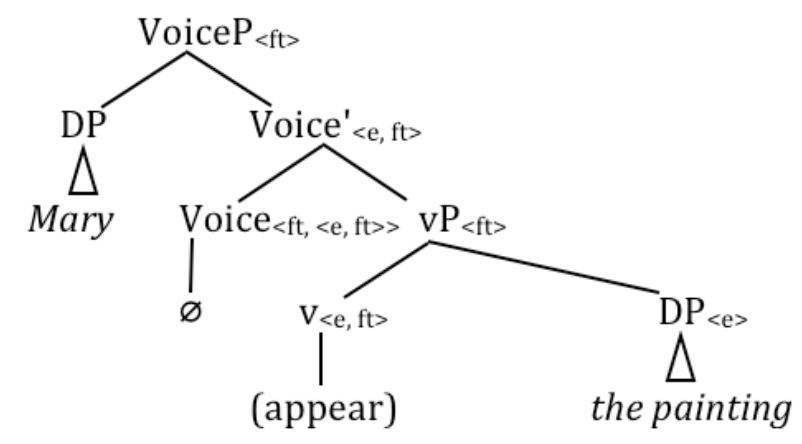

The VoiceP of the sentence in (27b) has the same structure as has the sentence in (27a), but with music as the complement of the v head. (27a) and (27b) however contrast in an important way that we have not yet addressed: with a bounded object such as a painting the predicate is telic, while with a unbounded object like music the predicate is atelic. One test for telicity is that telic predicates are acceptable with in phrases, as in (31a) while atelic predicates are marginal, or receive an inchoative reading (Vendler 1957); thus (31b), if it has any acceptable reading, can only mean that Mary started to make music at the end of an hour.

(31) a. Mary made a painting in an hour.

b. $\quad$ Mary made music in an hour.

The difference between the "bounded" and "unbounded" nature of the events in $(27 a, b)$ has been accounted for in the event-theoretic literature via Krifka's (1992) homomorphism function, which maps subparts of incremental theme objects to subparts of events; unbounded objects thus yield unbounded creation/destruction events. Within the force-theoretic framework, this relationship will hinge on the nature of causation and its interaction with the (non-)cumulative nature of the entity whose existence is the result of the force.

To implement this idea, we first must specify what in phrases mean. We propose, following Higginbotham (2000) and Giorgi \& Pianesi (2001), that in phrases specify the time between the beginnings of the temporal traces of two Davidsonian arguments; for us these arguments will be the situations referred to by init(f) and fin(f) ${ }^{22}$ The in phrase adjoins to the vP which is type $\langle\mathrm{f}, \mathrm{t}\rangle$ (and thus, incidentally, is not compatible with stative predicates, which are type $<\mathrm{s}, \mathrm{t}>)$. Let " $\tau\left(\mathrm{s}_{0}\right)-\tau\left(\mathrm{s}_{1}\right)$ " be the part of the temporal trace of $\mathrm{s}_{0}$ that does not overlap any part of the temporal trace of $\mathrm{s}_{1}$.

$\llbracket$ in an hour $\rrbracket=\lambda f$. duration $(\tau(\operatorname{init}(f))-\tau($ fin $(f)))=$ an hour

\footnotetext{
${ }^{22}$ Note that definition of force allows reference to fin(f) without having to look down further in the tree than the denotation of the $<\mathrm{f}, \mathrm{t}>$ node (either VoiceP or $\mathrm{vP}$ ) that it is adjoined to; thus we avoid having either to violate compositionality (see Dowty 1979:136 on exactly this issue, in his discussion of Tedeschi's (1973) account of progressive), or to explicitly chain Davidsonian arguments together (as Higginbotham (2000) does). It is exactly for this kind of case that we need to be able to identify a situation in terms of a force $\mathrm{f}$ through the use of the functions init and fin.
} 
In (31a), this works exactly as one might expect: for (31a) to be true, $\mathrm{s}_{0}$, the initial situation of the Mary-make-a-painting force, lasts an hour, until a painting exists, and it is at this point in time that $\mathrm{s}_{1}$ begins.

To see how in an hour interacts with Mary make music in (31b), we have to go into a little more depth. For this explanation, it is crucial that we have nowhere claimed that a result occurs after its cause - despite any temptation one might have to read temporal relations into our bubble diagrams of causal chains of situations. Aside from the discussion of for and in adverbials, where we had to appeal to a temporal trace function and a duration function, the force-theoretic framework says nothing about times at all, and in particular, nothing about the temporal relationship between a situation and its successor; our notion of succession of a situation is a causal notion ( $\mathrm{s}_{1}$ is the result of $\left.\mathrm{s}_{0}\right)$, not a temporal notion $\left(\mathrm{s}_{1}\right.$ is after $\left.\mathrm{s}_{0}\right)$. In short, temporal structure and causal structure are different, although related.

They are not entirely independent of each other, however. As Shibatani (1973) and Talmy (1976) point out, there are two temporal relationships that can exist between a cause and its effect. Either the cause provokes an effect that happens after the cause, or the cause provokes an effect that happens at more or less the same time as the cause (with at most a slight lag). Shibatani calls the first "ballistic causation" and the second "controlled causation". Jackendoff (1990:138) points out the same notions were identified much earlier by Michotte (1946/1963), who called them 'launching' and 'entraining' causation. Talmy makes the same distinction, between "point" and "extent" causation; McCawley (1976:119) distinguishes "continuous causation", and van Lambalgen \& Hamm (2005:43-45) propose "instantaneous" vs. "continuous" causation. In entraining (or continuous, or controlled, or extent) causation, temporal parts of causes are mapped to temporal parts of their effects. This mapping is analogous to Krifka's (1992) homomorphism between events and affected objects.

We assume, then, that it is perfectly possible for the (causal) successor of a situation $\mathrm{s}_{0}$ to happen at more or less the same time as $\mathrm{s}_{0}$. In $(31 \mathrm{~b})$, for example, the initial situation $\mathrm{s}_{0}$ (i.e. init(f)) includes Mary and certain of her properties, such as her intention to make music. The consequence of these properties is that she is the source of a Mary-make-music force such that some music starts to exist. But because of the mass nature of music, the moment there is a bit of music, then $s_{1}$, that is, fin(f), the result of the Mary-make-music force, is occurring as well; $s_{1}$ includes this music. Thus the reason that the in phrase is unacceptable is that there usually taken to be no interval between the beginning of $s_{0}$ and the beginning of $s_{1}$, because of nature of the existence criteria for an non-quantized individual like music. ${ }^{23}$

For coerced inchoative readings for stative predicates, such as The door was open in an hour, where the door is understood to become open at the end of an hour, we implement a standard coercion account driven by the type difference between the in phrase and the stative: a head must be added that introduces a force whose final situation is a door-open situation, so that the in phrase can be adjoined to a type $<\mathrm{f}, \mathrm{t}>$ node (for more on type-driven coercion in our framework, see section 5.2 below). ${ }^{24}$ Type-driven coercion is not, however, available for the

\footnotetext{
${ }^{23}$ Some incremental theme verbs, such as read, do not entail the creation or destruction of an object; for read, the relation which holds in the initial and final situation is not one of inclusion or exclusion but one of being read. The crucial claim is that the absence of a low-scope reading for for-an-hour adverbials in such cases indicates the absence of an embedded small clause in their syntactic argument structure representation, so that they necessarily do not involve the $\mathrm{v}_{\mathrm{BECOME}}$ predicate.

${ }^{24}$ Why must the coercion stop with $\mathrm{V}_{\mathrm{BE}}$.оME ? Why can't a VoiceP be added to introduce a source for the coerced inchoative force? I.e., why can't we then create *Mary is the door open in an hour with the meaning 'Mary opened the door after an hour'? Part of the answer is surely that coercion only needs the lower v head; the higher Voice
} 
inchoative reading of Activities with in phrases, such as Mary made music in an hour, since the vP Mary made music is already of type $<\mathrm{f}, \mathrm{t}>$. On the other hand, nothing in our world knowledge prevents the onset of $\mathrm{s}_{0}$, the causing situation of Mary's music, from beginning somewhat before the onset of $\mathrm{s}_{1}$. For example, Mary could have the intention to make music for a while (an hour perhaps) before starting to make music. Her intention is one of the properties in $\mathrm{s}_{0}$ from which the Mary-make-music force arises. Then, as desired, the temporal difference between the beginning of $\mathrm{s}_{0}$ and the beginning of $\mathrm{s}_{1}$ is indeed an hour; in this way the inchoative reading of dynamic predicates is derived.

\subsection{Manner verbs, resultatives, and motion predicates}

Verbs of creation and destruction are typically not as simple as 'make' or 'create', in which nothing is specified about how the creation or destruction transpires. In an articulated subevent syntax, more complex verbs are considered to modify the initiation or causation subevent (see, e.g. Levinson 2007, Ramchand 2008, Embick 2010). In the present framework, the lexical content of such verbs will be treated as predicates of forces, adding information about the nature of the force which is causing the creation or destruction of the incremental theme object.

We propose to adjoin such verb roots as manner modifiers of the vP, composing with it via Predicate Modification (as described above at the end of 4.1, postsyntactic m-merger will conflate the $\sqrt{ }$ write node with the $\mathrm{v}$ node to produce the surface form):

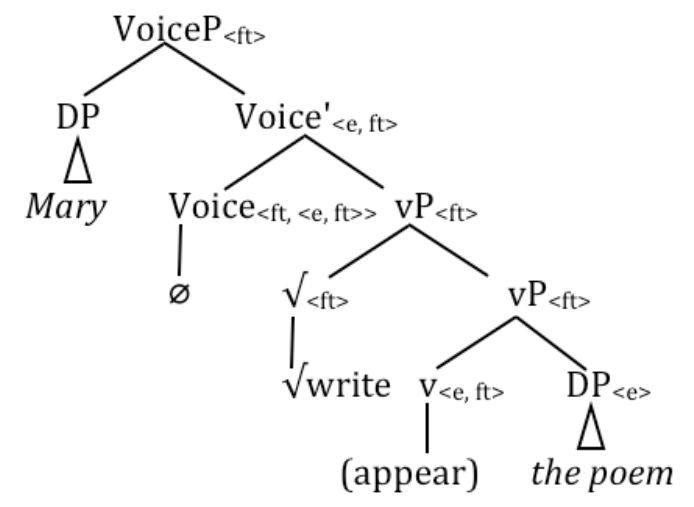

The verbal root $\sqrt{ }$ write denotes a property of forces as in (34a), in particular the property that is shared by certain patterns or configurations of force (in the sense of Gärdenfors 2007) that speakers agree to be writing. (Recall that multiple forces in the same situation can always be summed together abstractly to yield a single force.) The denotation of the higher $\mathrm{vP}$ will be as in (34b); the poem does not exist in the initial situation, and does exist in the final situation, and the kind of force that brings it thus into existence is a writing force.

$$
\begin{array}{ll}
\text { a. } & \lambda \mathrm{f} . \text { write }(\mathrm{f}) \\
\text { b. } & \mathrm{vP}=\lambda \mathrm{f} . \llbracket \text { the poem } \rrbracket<\operatorname{fin}(\mathrm{f}) \& \operatorname{write}(\mathrm{f}) \\
& \text { presupposed: } \sim[\llbracket \text { the poem } \rrbracket<\operatorname{init}(\mathrm{f})]
\end{array}
$$

head is superfluous. But strictly speaking, we cannot rule this structure out. 
The semantics of manner modification is thus straightforward. Indeed, this approach will suffice to analyze manner modification in contexts other than creation/destruction; since manner verbs are predicates of forces, they will always be eligible to adjoin to any node of type $\langle\mathrm{f}, \mathrm{t}\rangle$, and if the conditions on morphological Merger are met, thence be able to conflate with the $\mathrm{v}$ head and become the main verb of the clause. Resultatives and manner-of-motion constructions in English, as in (35a) and (35b) respectively, can be productively treated in exactly the same way. Instead of adjoining to type $<\mathrm{f}, \mathrm{t}>$ predicates headed by $\mathrm{v}_{\text {APPEAR, }}$, such manner expressions will adjoin to type $<\mathrm{f}, \mathrm{t}>$ predicates headed by $\mathrm{v}_{\mathrm{BECOME}}$ :

a. Mary hammered the metal flat.

b. Mary slouched toward Jerusalem.

We now turn to address activities, semelfactives, and their fellow-travellers, the verbs of birthing.

\subsection{Activity predicates, or, what calving has in common with dancing}

We begin by examining a relatively narrow verb class first considered in detail by Hale and Keyser (1993, e.g.): denominal verbs of birthing. They propose that such predicates involve an incremental theme object which is syntactically incorporated to become the root of the verb itself, as in The cow calved, The mare foaled, The otter pupped. ${ }^{25} \mathrm{We}$ adopt this approach to such predicates, incorporating a bare nominal predicate into a $\mathrm{v}$ head which is semantically the equivalent of $v_{A P P E A R}$ except in that it selects a predicate of individuals rather than an individual as its internal argument:

$$
\begin{aligned}
& \mathrm{V}_{\text {EMERGE }}=\lambda \mathrm{P} \lambda \mathrm{f} .[\exists \mathrm{y}<\mathrm{fin}(\mathrm{f}): \mathrm{P}(\mathrm{y})] \\
& \text { presupposed: } \sim[\exists \mathrm{y}<\operatorname{init}(\mathrm{f}): \mathrm{P}(\mathrm{y})], \operatorname{init}(\mathrm{f}) \text { is efficacious }
\end{aligned}
$$

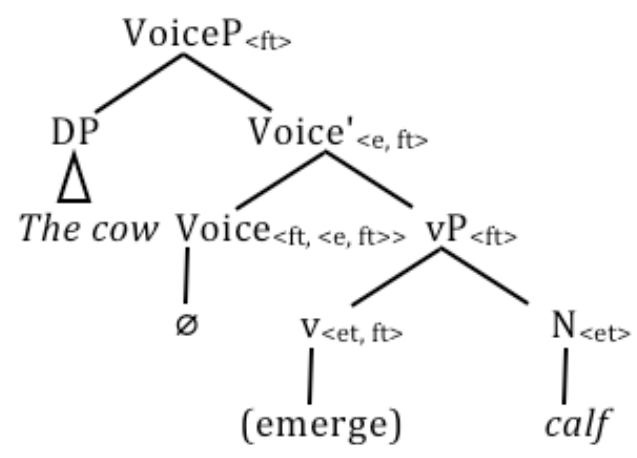

Treating such objects as incorporated equivalents of incremental themes is motivated by the fact

\footnotetext{
${ }^{25}$ The object coming into existence in transitive cases of $\mathrm{V}_{\mathrm{EMERGE}}$ comes out of the body of the source of the force. That is, although one can bleed or calve, one cannot poem or cake. This fact suggests that there is something about the incorporation into $\mathrm{v}$ that requires the source to be the literal physical source of the object, not merely the source of the energy which provokes the coming into being of the object. We don't know why this should be so, but it will be relevant to investigation of the nature of the Source relation in future work. See Folli and Harley (2008) for discussion of the notion of 'teleological capability', which may also be relevant here.
} 
that the telicity of these predicates is sensitive to the sortal quality of the incorporated predicate of individuals: incorporated count nouns produce telic verbs and incorporated mass nouns produce atelic ones (Harley 2005). For verbs describing types of birthing, the key contrast arises between calve (telic) and spawn (atelic), but verbs such as bleed, sweat and drool illustrate the same point: when the produced individual is a substance, rather than a spatially-bounded item, the resulting predicate is atelic, as expected if the incorporated nominal is behaving as an incremental theme:

(38) a. The cow calved in an hour.

b. The mare foaled in an hour.

c. \#The baby drooled in an hour.

d. \#The wrestler bled in an hour.

Harley (2005) claims that the Agentless analogue to such predicates (lacking the Voice projection) are denominal weather verbs, where the verb is formed from the noun denoting the emergent precipitation: rain, snow, sleet, hail, etc.

We are now in a position to consider the force-theoretic treatment of Activity predicates. Again, we follow Hale and Keyser (1993) in observing that such predicates are typically associated with a cognate noun (e.g., sing/song, work/work, dance/dance), and that their crosslinguistic counterparts are frequently complex predicates, composed of a light verb and a bare nominal. We treat these in the same way as the incremental theme and verb-of-birthing cases above, again with a type-theoretic difference in the argument selected by the light verb. In these cases, we assume that the incorporated nominal is a predicate of forces, and we gloss the verbal predicate as 'occur', rather than 'emerge'. We assume that a force can be "in" or "part of" a situation the same way an individual can: ${ }^{26}$

$$
\begin{aligned}
& \llbracket \text { dance } \rrbracket=\lambda f \text {. dance(f) } \\
& \text { VoCCUR }=\lambda \pi \lambda f .\left[\exists f^{\prime}<\operatorname{fin}(f): \pi\left(f^{\prime}\right)\right] \\
& \text { presupposed: } \sim\left[\exists f^{\prime}<\operatorname{init}(f): \pi\left(f^{\prime}\right)\right], \text { init(f) is efficacious }
\end{aligned}
$$

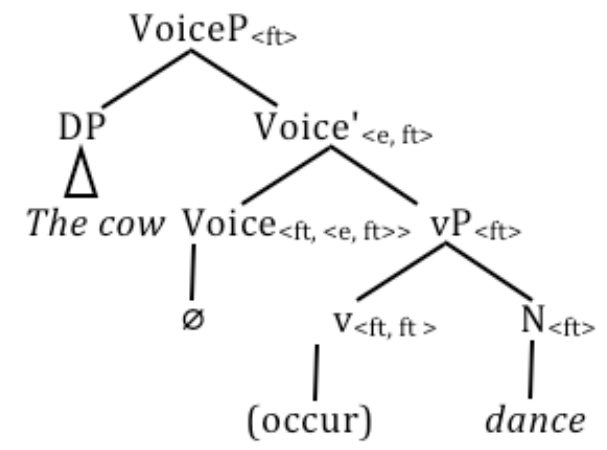

Verbs of emission, such as glimmer, gleam, beep, ring, etc. are also predicates of forces in this

\footnotetext{
${ }^{26}$ We assume that transitive Activities like push the cart are based on a root of type $<\mathrm{e},<\mathrm{ft}>>$, see Harley (2005) for discussion.
} 
same sense, derived from their cognate nouns. Again, the few such predicates which occur without a source-specifying Voice head are weather predicates; thunder is the best example of this in English. ${ }^{27}$

This analysis of Activities, it should be noted, refers to a similar causal structure as the analysis of Accomplishment predicates: the predicate refers to a force that provokes another situation. However, our Activities differ from our accomplishments in two ways. The first is that the $\mathrm{N}$ complement of $\mathrm{v}$ is a predicate describing a force that is instantiated in the result situation, rather than a result-state predicate of that situation, like [the door open] $]_{\mathrm{SC}}$; this in turn means that VOCCUR is type-theoretically distinct from $v_{\text {BECOME. }}$

The second way in which Activities differ from Accomplishments in the force-theoretic framework is that the temporal relationship between the causing force and the effect is different, as we proposed above in section 4.2. We propose that continuous causation is what happens in Activities: the result happens simultaneously with the causing force, instead of afterward. The temporal simultaneity is crucially not expressed in the semantics; the logical form makes no reference to temporal structure at all. Rather, it is a fact about the world that the particular force has a result that occurs either after or at the same time as the force itself. ${ }^{28}$

This dissociation of the causal structure from the temporal structure may not be plausible in a theory based on events, to the extent that it is implausible to think that there are two distinct events going on at the same time during an (e.g.) dancing event. (One theory with two Davidsonian arguments in Activities, that of Ramchand 2008, crucially places the events in a temporal sequence.) However, in a force-theoretic framework, it is not implausible to think that there is an exertion of energy in a dance-like manner, that results, more or less simultaneously, in a situation where there is a dance.

Semelfactives such as knock, flash, and pat (Smith 1991) are like Activities in that they name predicates of forces, and occur as complement to voccur. Semelfactives, however, impose an additional requirement on the subsequent situation $\mathrm{s}_{1}$ : The $\mathrm{s}_{1}$ of the force named by $\mathrm{a}$ semelfactive verb is required not to be a situation with an instance of a verbing force in it; this requirement gives semelfactives their 'cyclic' quality, as noted by Talmy (1985). Activity

${ }^{27}$ It is possible to make $\mathrm{v}_{\mathrm{BECOME}}$ more like $\mathrm{v}_{\text {EMERGE }}$ and vocCur. All three take a predicate as an argument: $\mathrm{v}_{\mathrm{BECOME}}$ takes a predicate of situations $\mathrm{p}, \mathrm{v}_{\text {EMERGE }}$ takes a predicate of entities $\mathrm{P}$, and $\mathrm{v}_{\text {OCCUR }}$ takes a predicate of forces $\pi$. In the latter two cases, we have existentially bound a variable ( $\mathrm{x}$, and $\mathrm{f}$, respectively) of which the relevant predicate is predicated. We could treat $\mathrm{v}_{\mathrm{BECOME}}$ the same, and existentially bind a situation $\mathrm{s}$ such that $\mathrm{p}(\mathrm{s})$; it requires only the assumption that a subsituation can be part of a situation in the way an individual or a force can be part of a situation. This equivalent $\mathrm{v}_{\text {BECOME }}$ would then have the denotation in (ib) instead of the one we proposed above in (19), repeated here as (ia):

$$
\begin{array}{ll}
\text { a. } & \mathrm{v}_{\mathrm{BECOME}}=\lambda \mathrm{p} \lambda \mathrm{f} \cdot \mathrm{p}(\mathrm{fin}(\mathrm{f})) \\
& \text { presupposed: } \sim \mathrm{p}(\operatorname{init}(\mathrm{f})) \\
\text { b. } & \text { equivalent } \mathrm{v}_{\mathrm{BECOME}}=\lambda \mathrm{p} \lambda \mathrm{f} .[\exists \mathrm{s}<\operatorname{fin}(\mathrm{f}): \mathrm{p}(\mathrm{s})] \\
& \text { presupposed: } \sim[\exists \mathrm{s}<\operatorname{init}(\mathrm{f}): \mathrm{p}(\mathrm{s})]
\end{array}
$$

However, we continue to prefer (ia) because it is simpler.

\footnotetext{
${ }^{28}$ As is well-known, there is a coerced reading of Activities with in an hour modifiers, (e.g., Mary ran in an hour) to the effect that there is a specifically planned satisfactory amount of running that Mary did in an hour. This is a case, like ordinary incremental-theme telics, where the result-here the point where Mary's running reaches an agreed-upon or accommodated standard - occurs at the conclusion of the application of the Mary-running force. That is, a sortal/quantized interpretation is imposed on the incorporated predicate of forces. The same would apply to Mary made music in an hour, etc.
} 
predicates do not have such a requirement.

Again, as predicates of forces, these roots are predicted by virtue of being type (f,t) to participate freely as manner predicates (composing with vP via Predicate Modification) in change of state and resultative constructions (i.e., with $\mathrm{v}_{\mathrm{BECOME}}$ ), and are equally expected to appear as activity predicates (i.e., with VOCCUR), a pattern which has long been observed in the lexical-semantic literature:
a. She hammered.
b. She hammered the metal flat.
c. She laughed.
d. She laughed him out of the room.

Indeed, they can also combine as manner predicates in incremental theme constructions (i.e., with $\mathrm{v}_{\text {APPEAR }}$ ), as expected given their type, producing the well-known hyponymous object and cognate object cases:
a. She danced a jig.
b. She sang a song.

Verbs of birthing can also participate in cognate object/hyponymous object incremental theme constructions, as in She calved a beautiful heifer or She sweated bullets/blood/Gatorade; similarly, in robust manner-incoporating langauges like English, they can occur as manners in change-of-state structures:
a. She sweated her way to Carnegie Hall.
b. He bled to death.

In the framework here, the well-formedness of such cases (which are subject to cross-linguistic parameterization) must result from a type-coercion operation which lifts these predicates of individuals into predicates of forces, enabling them to behave as manner modifiers.

This latter observation raises the possibility that all of these nominal verb roots (including dance, sing, etc.) are predicates of individuals that are type-shifted to predicates of forces when

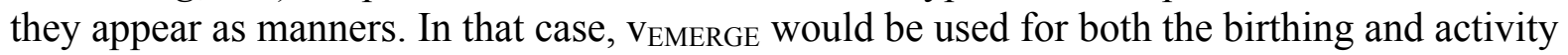
verb classes. However, there are empirical reasons to think that the ontology of nominal predicates needs to include both predicates of individuals and predicates of forces. Activity roots in the event-based literature are treated as predicates of events (see, e.g. Marantz 2001 Levinson 2007, Embick 2010) because the corresponding nouns interact differently with predicates like begin. Nouns like dance can serve as subjects of begin: The dance began (at $2 o^{\prime} c l o c k$ ). Nouns like calf or cake, however, cannot: \#The calf began (at 2 o'clock). (See Pustejovsky 1995, Pylkkänen et al. 2009 for further discussion of begin as a rigid type selector.) In this framework, such facts motivate our treatment of activity roots like dance or sing as predicates of forces, type $<\mathrm{f}, \mathrm{t}>{ }^{29}$

\footnotetext{
${ }^{29}$ Roy and Soare (2013) present an argument that the event involved in such nouns is at the conceptual or lexical level, while grammatically they are predicates of individuals (type $<\mathrm{e}, \mathrm{t}>$ ). We will not take up this idea here although we find it interesting, especially as, given the dual nature of forces as functions (in the linguistic system) and inputs of energy (in the conceptual system), we also need to make reference to a mapping from logical form to a conceptual level that is not the lexicon. See Copley \& Harley (in prep.).
} 
A welcome result of treating activities as referring to the final situation of a force is that it suggests a characterization of Japanese -te iru. As, e.g.,Ogihara (1998) shows, -te iru tends to be translated as the English progressive in combination with activities, as in (45a), and as a resultative with telic predicates, as in (45b).
a. Taroo-wa warat-te iru.
Taroo-TOP laugh-te iru
'Taroo is laughing.'
b. Taoru-wa kawai-te iru. towel-top dry.intr-te be
'The towel has dried.'

Ogihara's unification of these readings takes advantage of partial events, saying that a -te iru sentence is true when an event occurs at the reference time and e is a part of a larger event. A more recent account of -te iru (Nishiyama, 2006) is rather similar to Ogihara's, but uses both partial events and inertia worlds as per Portner (1998). However, as we have argued above in section 1.1, the move to partial events is problematic in that nothing is said about the conditions under which one event can be 'part of' another, when the culmination of the larger event may or may not happen. The move to inertia worlds may be problematic in the other direction: there is semantics in the logical form that could (and, we think, should) be put into the cognitive system. In our framework, the denotation of -te iru need only say of the reference situation that it is the final situation of a force with the desired property. Recall that "pred(s)" picks out the predecessor situation of $\mathrm{s}$.

$$
\llbracket \text {-te iru }=\lambda \pi \lambda s . \pi(\operatorname{net}(\operatorname{pred}(s)))
$$

For a telic predicate, the final situation is the result state that begins after the initial situation, yielding the resultative interpretation, while for an Activity, the final situation is a situation that is almost entirely cotemporaneous with the initial situation, so these cases receive an ongoing reading. ${ }^{30}$ Such an account of -te iru fits very well with the idea (Hasegawa 1996) that -te acts as a link between clauses conveying that the -te linked clause describes a situation that precedes the

${ }^{30}$ A third reading is an 'experiential perfect' (Comrie 1976) reading:

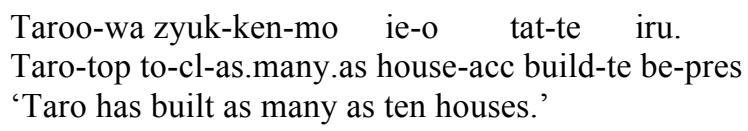

Nishiyama's theory accounts for this perfect reading, in addition to the other readings, via a free property variable, which is asserted to hold of the present situation and whose value is determined pragmatically. This free variable is intriguing in light of the fact that some cases that Talmy brings under the umbrella of forces, such as but not limited to intentions, require reference to propositions. Elsewhere (Copley 2010, Copley \& Harley in press) we have proposed that a "second-order" force function of type $<\mathrm{s},<\mathrm{s}, \mathrm{t}>>$ (cf. "first-order" force functions of type $<$ s, $\mathrm{s}>$ ) to account for these. In this case, we find it plausible that a situation such as Taroo's building of houses may have irreducible and indeed force-like relationships with propositions, such as the fact that Taroo has built as many as ten houses. This is a good example of the fact that a force-theoretic approach need not always conflict with existing proposals about aspect and telicity; it has the potential, however, to provide reasons why certain temporal and causal relationships would be expressed in language, namely because they are related to a certain representation of causal structure. 
situation described by the main clause in a causal or intentional sequence, an idea that is mysterious if -te is held to have a partial-event imperfective reading as in (45b).

\subsection{Agents and Causers as sources of forces}

Thus far, we have treated the external arguments of all Aktionsart types identically, namely, as the subject of a 'source' predicate expressing a relationship between an individual and a predicate of forces, introduced by the Voice head. ${ }^{31}$ We now provide some explication of our notion of 'source', connecting it to the literature on external argument thematic relations more generally, and to the launching/entraining causation distinction from the force-dynamic literature which has already been alluded to above.

Animate and inanimate external arguments can exhibit distinct interactions with argument-structure and Aktionsart classes. The literature on thematic relations has examined this distinction in detail, without coming to any consensus on the qualia that underlie these interactions. A common distinction is made between volitional and non-volitional entities, which are often termed "Agents" and "Causers" respectively (of course, a volitional entity can be a Causer if its action is non-volitional). The Agent/Causer distinction also bears on the Aktionsart type of the predicate: Causers seem to be more restricted, in that they typically only appear as the external arguments of change-of-state predicates, while Agents can also be the external arguments of Activity and Semelfactive predicates.

Analyses differ, however, on whether such distinctions are taken to be visible in the grammar. Ramchand (2008), for example, subsumes all external arguments under a single 'Initiator' role. Hoekstra (1984) and Higginbotham (1985) deny any particular relational content to the external argument role at all: external arguments are simply notationally designated as such, without giving an event-structural or thematic 'name' to their relationship with the predicate. In contrast, Beavers and Zubair (2013) propose that the Agent/Causer distinction depends on whether the effector of a change is a dynamic or a stative event.

So far in our development of the force-theoretic framework we have made a similar assumption, treating both Agents and Causers as sources of forces. We use the term 'source' in quite a literal sense to indicate that in both cases, the argument introduced by Voice is the origin of the energy that is put into the situation; they thus play a 'leading role' in determining the net force of the situation. There is least one way in which Agents are distinct from Causers, which is that they become the sources of forces by virtue of their intentions, rather than by virtue of their physical properties. Copley and Harley (in press) formulate a Law of Rational Action to mediate the relationship between having an intention and generating a force (see also Kamp 2007 and Copley, 2010 for explicit proposals for linking intentions to actions). Agents are subject to the Law of Rational Action because they have the ability to intensionally represent a goal. Another obvious difference is that Agents have the ability to create energy spontaneously, as if by "magic", while, for instance, a thrown object is dependent on its motion and mass for the (kinetic) energy it provides to the situation. In general, we expect that distinctions which in previous work have been ascribed to the distinction between Agents and Causers have their basis in facts about the relative abilities of Agents and Causers. We discuss the two aforementioned

\footnotetext{
${ }^{31}$ Note that we do not appeal to syntactically-expressed chains of subevents: the difference between a causative and an inchoative verb is simply the explicit inclusion of a source argument, introduced by an active Voice head. Anything that looks like chaining emerges from the semantics for forces.
} 
special abilities of Agents here, beginning with the notion of energy-generation and its connection to launching vs. entraining causation and Aktionsart classes, and then returning to briefly investigate some consequences of volitional Agents' ability to intensionally represent goals.

Agents can be the external arguments of Activities as well as change-of-state predicates, as in (49a). In contrast, Causers cannot be the external argument of Activities, as reflected by the need for the telicizing resultative adjective raw in (47b), or the particle up in (47d) (see Folli and Harley 2004 for extensive discussion, among others).
a. John rubbed his skin.
b. $\quad$ The saddle rubbed his skin *(raw).
c. The cow chewed its cud.
d. The washing machine chewed the laundry *(up).

Recall that Activities in the force-theoretic framework involve what McCawley (1976) and van Lambalgen and Hamm (2005), e.g. call "continuous causation," where a result situation occurs at more or less the same time as the initial situation, perhaps with a brief initial lag. We would like to suggest that the explanation for the contrast in (47) turns on the idea that the ability to generate energy throughout a situation is necessary for continuous causation (compare the notion of 'event-to-event' homomorphism from Levin and Rappoport Hovav (2005), Rappoport Hovav (2008); or the notion of 'entraining' causation in contrast to 'launching' causation (Michotte 1946/1963, Shibatani 1973, etc.). Beavers and Zubair (2013) show that in Sinhala, so-called 'volitive' marking depends on exactly the property of being able to generate a dynamic eventuality, which maps naturally to the notion we are discussing here.

Volitional entities have the ability to generate energy quite generally; Folli and Harley (2008) have argued that the notion of Agent should be extended to include certain special inanimate objects which are 'teleologically capable' of generating the energy needed to produce certain specific forces (e.g., The kettle whistled, The wind moaned). This energy arises also in a kind of magical way, in that it is not perceptibly transmitted spatiotemporally from other objects. However, unlike for volitional Agents, it is not generated in response to the interaction of intentions with the Law of Rational Action. Consequently, such inanimate but telelogically capable Agents are more constrained in the kinds of forces they can generate; in typical examples it is only the one or two kinds of forces they were designed to produce (in the case of artifacts) or stereotypically do (as in the case of the wind, the sea, etc.).

Like the ability to generate energy, the ability to represent a goal will also have repercussions for the kinds of forces that can be generated by an entity. It is the Agent's representation of the goal that unifies the disparate sub-forces of picking up a pen, cogitating, writing, redacting, etc. into something we understand as a "write-a-poem" force with a final situation in which a poem exists; a Causer cannot write a poem because it lacks the intention that would glue these subforces together as goal-directed action (see also Tovena 2011, e.g. for a related idea). Likewise, an activity of getting paint on something is only 'painting' if there is an Agent that intends it to be (\#The explosion at the paint factory painted it, Kiparsky (1997), see also McCawley 1971, Fodor 1981). The ability to intensionally represent goals also proves crucial to futurates such as The Red Sox play/*defeat the Yankees tomorrow, as in Copley (2008, 2014), and have-causatives (Copley \& Harley 2010).

The properties that Agents have of being able to generate energy and (for volitional Agents) of being able to represent a goal can therefore account for contrasts between Agents and 
Causers. For the cases we have discussed, we need not posit that the grammar has access to these properties; rather, these are simply constraints on the kinds of forces that can be produced by any particular entity, on the basis of its abilities. Copley \& Wolff (in press) further develop this point to argue that the key property that subsumes both Agents and Causers is that of causal disposition, where volitions are a special kind of disposition.

If this conceptual story is the whole story, we would expect that argument structure would not be sensitive to any distinction between Agents and Causers, in particular, the ability to represent goals intensionally should not be visible to the grammar. So far, the only thing the grammar sees is the source relation, which pertains to Agents and Causers alike. If this is the case, however, something more should be said about the status of a certain body of empirical evidence that seems to suggest the need for an Agent/Causer distinction in the grammar.

\subsection{Cause-introducing PPs}

One set of arguments for a distinct Causer or Cause role comes from the debate over anticausativization approaches to inchoative predicates. As we will see, it has been argued that certain data from adjoined PP phrases pick out all and only Cause arguments in dynamic predicates. $^{32}$

The $b y$-phrase in a passive introduces exactly the set of external arguments that active Voice can (Williams 1981), and is ill-formed with unaccusative predicates (see Bruening 2012 for a recent account). In contrast, from-phrases seem to introduce only Cause external arguments, and are well-formed with unaccusatives. This range of facts is illustrated in (50). The by-phrase can introduce anything that can be the external argument of the corresponding transitive active clause, but cannot co-occur with the unaccusative. In contrast, from can only introduce nonagentive external arguments: the sentence in (48c) is not felicitous in a case where John is the Agent of an action that warms up the sidewalk (though it is acceptable if it is his body heat that warms the sidewalk).

(48) a. The sidewalk was warmed up by John/by the sun.

b. The sidewalk soon warmed up from the sun.

c. \#The sidewalk warmed up from John.

This compatibility of from-phrases with inchoatives, and the special constraints on the kind of arguments that from-phrases can introduce, have been taken to show the need for causing events in the semantic representation of inchoative predicates, and such data has been central to the anticausativization vs. causativization debate over the causative/inchoative alternation. (Chierchia 1989/2004, Piñon 2001, Alexiadou, Anagnostopoulou and Schäfer 2006, Kallulli 2006, Schäfer 2007, among many others)

Along the same lines, Chierchia (1989/2004), introduces another test which he claims picks out all and only sentences with either Agent or Causer subjects: the availability of by Xself adverbials. Levin and Rappaport Hovav (1995), Koontz-Garboden (2009) and Beavers and Zubair (2013) also adopt this diagnostic. Since by Xself is possible with inchoative predicates such as the one in (51), Chierchia concludes that inchoatives are underlying two-place causative

\footnotetext{
${ }^{32}$ Causes, as discussed in the event structure literature, seem to be a subset of the argument which in the thematic role literature are called Causers; in particular, Causers include all non-volitional initiators of changes of state, while Causes are specifically only the events which are the first argument of a CAUSE relation.
} 
relations with the external Causer role bound by reflexivization to the internal Theme role (with reflexivization overtly marked in languages like Italian).

The door opened by itself.

We argue, in contrast, that neither from-PPs nor by Xself PPs actually indicate the presence of a causer or causing event in the semantics of these predicates. With respect to fromPPs, our contention is based on the little-commented-upon fact that such PPs can modify stative predicates, as well as dynamic ones:

(50) a. The sidewalk was warm from the sun.

b. John was pink from embarrassment.

It would seem implausible to analyze stative predicates like be warm or be pink as introducing a causing eventuality argument in addition to the eventuality argument representing the state; they do not behave like dynamic eventualities (\#The sidewalk was being warm; \#John was being pink., etc.) Consequently, it seems clear that from-PPs do not diagnose the presence of a Cause argument in the semantics of the predicates to which they adjoin (though they may introduce one).

Similarly, Alexiadou, Anagnostopoulou and Schäfer (to appear), in line with the conclusions of Piñon (2001), Alexiadou et al (2006), Schäfer (2007) a.o., argue at length that by Xself phrases do not diagnose all and only predicates with Agent or Causer subjects. They give examples where the antecedent of by Xself cannot be a causer, as in adjectival copula constructions:

(51) 300 million years ago the climate became warmer by itself and without human intervention.

They conclude, with Reinhart (2000), Pylkkänen (2002), among others, that by Xself simply denies the participation of any identifiable Agent or Causer; in the current framework, it would deny the existence of a Source argument for the net force of the preceding situation. They conclude that anticausative predicates lack an implicit external argument of any kind. (See also Schäfer and Vivanco (2013) for explicit argumentation against Koontz-Garboden's reflexivization approach.)

While we will not provide a full treatment of the properties of these PP adjuncts here, the tools made available in the force-theoretic framework do suggest an intuitively plausible line of anlaysis for the from-PPs. The event-theoretic literature has argued that the DP argument introduced by a from-PP names a causing event; this corresponds here to the natural idea that such a DP names a force (remember we used a similar idea above in section 4.4 in discussing the meaning of NPs such as dance). In this light, consider the data in (52) below. (52a) and (52b) contain DPs that seem like good candidates for names of forces; both DPs are felicitous in a from PP. The ball (52c) seems to just possibly be elliptical for the action/motion/energy/force of the ball and with that interpretation, the from phrase is just possible. (52d) is infelicitous, even if we try to understand it thus elliptically; the elephant cannot be elliptical for the force exerted by the elephant. The ill-formedness in (52e) is similar to the ill-formedness in (52d). In the last two (or three) examples, the name of an Agent cannot be elliptical for the name of a force exerted by that 
Agent. ${ }^{33}$ In short, from-phrases require as arguments DPs that name forces.

(52) a. The window broke from the earthquake

b. The window broke from the ball's hitting it.

c. ?The window broke from the ball.

d. The floor broke from the *(weight of the) elephant.

e. The window broke from John*('s hitting it).

It is also worth noting that such from-phrases are compatible not just with causative change-of-state predicates (as suggested by the 'cause' analysis in the event literature) but also with unergative predicates, as in (53), as long as the force named by the DP argument of from directly provokes the force described by the predicate $\left(\mathrm{f}_{0}\right)$. Call this provoking force $\mathrm{f}_{-1}$, as it (and the situation $\mathrm{s}_{-1}$ ) are directly causally precedent to $\mathrm{s}_{0}$ (and thus to $\mathrm{f}_{0}$ ). There are two ways that this can happen, depending on whether source of $f_{0}$ generates the force by virtue of the Law of Rational Action (i.e., voluntarily), or by some other means (i.e., involuntarily). If the source is voluntary, as in $(53 \mathrm{c}, \mathrm{d})$, then $\mathrm{f}_{-1}$ can only be a desire or volition; this is the same as saying that in voluntary action, the most immediate "cause" of the force is always volition. If, on the other hand, the source is involuntary, then $\mathrm{f}_{-1}$ can be something other than a desire, as in $(53 \mathrm{a}, \mathrm{b})$.
a. Mary cried out from anger.
b. John groaned from the pain.
c. Sue called John from a desire to see how he was/\#from the pain.
d. The university was shut down (by the governor) from a desire to protect the students/\#from the riots.

Insofar as it is plausible for DPs to be names of forces as well as individuals (just as, in the event-theoretic literature, DPs can name events, pronominally refer to events, etc.) the forcetheoretic framework gives us the tools needed to address the range of facts here. A from-PP adjoins to a predicate of situations (presumably AspP, as do for-PPs, see section 4.1 above) and introduces a relation between the force named by its internal argument and a situation s, namely that the force was the net force of the situation preceding s:

$$
\llbracket f r o m \rrbracket=\lambda f \lambda s . \operatorname{net}(\operatorname{pred}(s))=\mathrm{f}
$$

Such force-naming DPs can also serve as external arguments introduced by the Voice projection, as in The earthquake broke the window. In event-theoretic approaches (e.g. Bach 1986) events are analogous to individuals; in the present framework the same will be true of forces (though see fn. 46 for further discussion).

\footnotetext{
${ }^{33}$ The exact conditions on this kind of ellipsis require further investigation, but we note that it seems to be impossible to understand an individual-denoting DP as an elliptical name for a force when the force is produced by the interaction of the individual with the normal field (footnote 16) via either the gravitational field, as in (52d), or the Law of Rational Action, as in (52e)), as opposed to a (more) direct transmission of energy. These constraints are like the conditions on the application of 'reference transfer functions' discussed by e.g. Jackendoff 1997:54, with respect to cases like 'The ham sandwich wants a cup of coffee', referring to a restaurant customer, not a ham sandwich.
} 


\section{Dynamic and stative predicates}

Now that we have presented our implementation of the syntax-semantics interface for verbal argument structure, we take a step back to consider the relationship between the technical apparatus presented here and Davidson (1967)'s original data. One of the major kinds of evidence supporting the reification of events was the interpretation of adverbial modifiers. We differ from Davidson in what we think the arguments he discovered really are - as we have argued above, we consider them to be reified forces rather than reified events - but we are good (neo-)Davidsonians in supporting modification by means of arguments.

While Davidson's article explicitly treated only what he called "action sentences", it was evident that certain stative sentences can also pass many of his modification tests; this has been taken to show (e.g. Kratzer, 1995) that such statives have to have a Davidsonian argument as well, as shown in (55):

Mary was happy in the living room.

However, it is clear that not all modifiers are created equal. Thomason and Stalnaker 1973 pointed out that certain adverbials which are good modifiers of action sentences (e.g. quickly) cannot modify stative sentences, and proposed to distinguish the two types of predicates with a diacritic to which adverbial modification is sensitive. However, they did not introduce a clear type-theoretic contrast to distinguish these two classes of eventualities.

We would like to draw attention to the fact that the force-theoretic framework provides a more fine-grained ontology for Davidsonian arguments. ${ }^{34}$ We have two types of arguments that can serve Davidson's purposes, situation arguments and force arguments. In fact, we have already made use of this distinction in accounting for the distribution of two temporal adverbial phrases: for-phrases (see (26b)) take situation arguments, while in-phrases (see (32)) take force arguments. This gives us the ability to attack the so-called 'eventive' vs 'stative' distinction with type-theoretic tools, though for reasons that should be evident, we will prefer the term "dynamic" to the term "eventive" when referring to non-stative predicates.

In this section, we will analyze several of the conundrums related to this distinction in terms of our type-theoretic difference between forces and situations. We will first show that it is easy to analyze Katz's (2003) generalization about Thomason \& Stalnaker's two classes of adverbials. We then provide an implementation of aspectual coercion in response to type clash with the selectional requirements of progressives and imperatives. We subsequently demonstrate that the force/situation distinction gives us the tools needed to propose a novel formal analysis of a mainstay of the force-dynamic literature: 'maintaining' predicates such as keep and stay.

\footnotetext{
${ }^{34}$ Of course, we need to consider as well whether it is too fine-grained. An anonymous reviewer reminds us that one of the attractions of Davidson's proposal was a simplified mapping between nominal and verbal modification: adjectives and adverbs are both predicates of a basic-type argument, either an individual or an event. The ontology we adopt here is more complex. On reflection, we expect mappings between predicates of individuals and predicates of situations to be as straightforward as it was for Davidson. The only issue arises when we consider how modifiers of predicates of forces might map to the nominal domain. But note that the adjectival form quick of the predicate of forces quickly combines only with nominals which themselves are felicitously treated as predicates of forces, as diagnosed by, e.g., the begin test (see discussion in section 4.4 above). Compare, e.g., a quick lunch with \#a quick calf. This being the case, it seems that the finer-grained division we propose here are likely to be appropriate in the nominal domain as well as the verbal domain.
} 


\subsection{Adverbial selection}

As aluded to above, Thomason and Stalnaker (1973) observed that certain adverbial modifiers (what they called 'VP-adverbs') are incompatible with stative predicates, although others ('Sadverbs') can modify both stative and dynamic predicates:
a. *John loved Mary quickly.
b. John kissed Mary quickly
a. John probably loved Mary.
b. John probably kissed Mary.

They proposed that the sensitivity of VP-adverbs such as quickly to the difference between stative and dynamic predicates indicates that there is a need to distinguish the two classes via a diacritic visible to VP-adverbs.

Katz (2003) points out that there is a crucial asymmetry in the classes of adverbs which are sensitive to this feature. While there are adverbs which modify dynamic predicates and are incompatible with stative predicates, as in (58), there are no adverbs exhibiting the reverse pattern, compatible with only stative predicates -- the pattern illustrated in (59) does not occur, i.e. there is no adverb with the distribution of blickly. All adverbs capable of modifying stative predicates can also modify dynamic ones, as in (60). Katz calls this the Stative Adverb Gap.

(58) a. John kissed Mary quickly.

b. *John knew Mary quickly.

(59) a. *John kissed Mary blickly.

b. John knew Mary blickly.

(60) a. John kissed Mary a long time ago.

b. John knew Mary a long time ago.

What's needed to account for the Stative Adverb Gap is for dynamic predicates to share something with stative predicates, so as to enable combination with adverbs like a long time ago, but also have an additional property, which stative predicates lack (Galton 1984 and Herweg 1991, e.g.), that allows them to combine with adverbs like quickly. The failure to combine should be the product of a type-clash. Katz proposes that statives lack a Davidsonian event argument. From this it follows that only dynamic predicates are compatible with adverbials that select for event arguments (i.e. Thomason and Stalnaker's VP-adverbs). But since both dynamic and stative predicates ultimately become predicates of times higher in the structure, they are both modifiable, at these higher nodes, by temporal adverbs.

The force-theoretic framework also provides a type distinction between dynamic and stative predicates on which such adverbial selectional behavior can depend: dynamic predicates are predicates of forces, while stative predicates are predicates of situations. ${ }^{35}$ As in Katz's

\footnotetext{
${ }^{35}$ Beavers and Zubair (2013) also propose to distinguish type-theoretically between states and events, while maintaining the overall notion of a supercategory of 'eventualities'; however, their implementation does not obviously allow for the capture of the one-way implicational relation between the categories that Katz's data requires.
} 
approach, it further automatically provides the shared property, because predicates of forces become predicates of situations via the operation of Aspect. ${ }^{36}$ Consequently, we expect any adverb that can compose with stative predicates to also be able to compose with dynamic predicates, a property we already have seen above in our treatment of for-modification (section 4.1).

Because stage-level stative predicates in the force-theoretic approach have a situation argument, it is possible that the present analysis has an advantage over Katz's, in allowing us to maintain Kratzer (1989)'s distinction between stage and individual level stative predicates, which is lost in Katz's approach. In the current proposal, stage-level statives have a situation argument, and hence also a temporal trace, and we can happily assume that individual-level statives are predicates of individuals, as Kratzer proposed. ${ }^{37}$

\title{
5.2 Coercion
}

As Katz shows, the availability of a type-distinction between stative and dynamic predicates also has significant advantages in accounting for the dynamic readings acquired by some stative predicates in morphosyntactic frames that normally require dynamic predicates. For example, although the English progressive was one of Vendler's original tests for stative vs. dynamic predicates (as in (61)), it has long been recognized that certain predicates thought to be stative because they can occur in episodic readings with the simple present, as in (62), can indeed occur with the English progressive, as in (63) (Partee 1977, Dowty, 1979, Smith 1983, Bach, 1986, de Swart 1998, Rothstein 2004, a.o.):
a. John was smoking.
b. \#John was knowing French.
a. Mary loves her new neighbors.
b. John is very smart about this.

\begin{abstract}
${ }^{36}$ An anonymous reviewer points out that not all adverbials that combine with both stative and dynamic predicates plausibly combine above Aspect, e.g., intentionally, which refers to properties of the subject argument and therefore might naturally be thought to adjoin below Aspect. In that case, such adverbs must have two types, $<$ s, $t>$ and $<$ f, $>$. We don't see this as a problem, however, since this point pertains only to adverbials that are related to the subject's intentions such as regretfully, considerately, etc. There is independent evidence that intentions and their results can be either stative or dynamic, and that the stative-dynamic difference, even for intentions, is visible to the grammar. See the discussion on the representation of goals in section 4.5, and the contrast in (i), which shows that have causatives (which encode the matrix subject's intention) can be either stative or eventive, and that this difference affects aspectual selection in the usual way.
\end{abstract}

a. Mary has/*is having John running errands.

b. Mary has/is having John run errands.

*has on episodic reading

We conclude that it is appropriate to allow adverbials like intentionally to modify both stative and dynamic predicates.

${ }^{37}$ It is possible, also, that treating stage-level statives as predicates of situations, rather than predicates of times, provides (like Kratzer's) a more perspicuous account than Katz's of certain non-temporal adverbials that can modify such predicates: In a sentence like Mary was happy in the kitchen, for example, it seems that the Davidsonian argument being modified by the location predicate is not obviously temporal in character. 
(63) a. Mary is loving her new neighbors.

b. John is being very smart about this.

Likewise, some stative predicates can occur in imperatives which are also supposed to select dynamic predicates, as shown in (64) and (65):

(64) a. Smoke!

b. \#Know French!

(65) a. Love thy neighbor!

b. Be smart about this!

Rather than multiply lexical entries to account for the apparently variable eventiveness of these predicates, we assume (with Moens and Steedman 1988, Smith 1991, de Swart 1998, a.o.) that these are examples of coercion. Other prototypical cases of coercion have been profitably treated as type-driven; for example, sentences like John began the book arguably coerce an entity into an event (Pustejovsky 1995, Pylkkänen et al. 2009); see also Bale and Barner (2009) on coercion between count and mass readings of bare nominals. In event-based frameworks without a type distinction between stative and eventive predicates, the coercion of a stative to an eventive predicate cannot be treated as type-driven.

We can take advantage of the present type-theoretic distinction between stative $(<\mathrm{s}, \mathrm{t}>)$ and eventive $(<\mathrm{f}, \mathrm{t}>)$ predicates to motivate an account of coercion in progressive statives. The progressive, we proposed above in (17), selects an $\langle\mathrm{f}, \mathrm{t}\rangle$ predicate. When a progressive or an imperative is applied to a stative predicate like John love Mary, the type mismatch triggers a type shift from $<\mathrm{s}, \mathrm{t}>$ to $<\mathrm{f}, \mathrm{t}>{ }^{38}{ }^{38}$

It is worth noting that although it has been claimed that the subject of coerced stative progressives has to be volitional, this is not actually the case. Rather such subjects are restricted by the usual constraints on the external arguments of Activity predicates discussed in section 4.5 above. While they need not be volitional, they must exhibit teleological capability because the result of such coercion is an activity. In examples like John is not being smart about this or Mary is being silly, the Activity can certainly be non-intentional; cf. also The sea is being awfully aggressive today.

\subsection{Verbs of maintaining}

The third case in which the force-based treatment provides formal insights into the dynamicstative distinction involves a classic case from the cognitive force-dynamic literature, namely verbs of maintaining. They are canonical examples of the way in which lexical meanings refer to agonist/antagonist relationships, revealing the need for a Davidsonian argument that refers to a force rather to an event. Above we outlined the issues raised by such verbs, like keep and stay, which are clearly dynamic (as shown by examples $(8,9)$ above, repeated below as $(66,67)$ ) but which do not involve a change of any kind.

\footnotetext{
${ }^{38}$ We here remain agnostic concerning the mechanism by which the type shift is implemented, whether purely in the semantic representation or whether by means of an additional layer of structure. We also leave for future research the question of the conditions under which this shift is possible.
} 
(66) a. The rock is keeping the door open.

b. The door is staying open.

(67) a. The rock keeps the door open.

b. The door stays open.

These verbs are paradigm cases in the cognitive linguistics literature on force dynamics, but are not often discussed in event-theoretic approaches.

We can imagine several event-based analyses for keep, but they seem unsatisfactory. We assume that keep and stay, like other causative predicates, take a small clause complement. In a sentence such as The rock kept the door open, this complement would be [the door open]). The problem with event-based (68a) ("cause to be") and (68b) ("cause to become") is that it is possible to keep something in a location without strictly being the cause of its being there or of its coming to be there. On the other hand, keep might instead be "cause to stay," as in (68c). But in considering an event-based approach to stay, as in (68d), we run out of options: there can be no external argument or causing event, and there is no obvious way to combine the caused event and the proposition denoted by the small clause in such a way as to reflect the fact that stay is not the same as $b e .{ }^{39}$
a. $\llbracket k \operatorname{keep} \rrbracket(\mathrm{x})(\mathrm{p}) \quad=$ ?
$\operatorname{Agent}\left(\mathrm{x}, \mathrm{e}_{1}\right) \& \operatorname{CAUSE}\left(\mathrm{e}_{1}, \mathrm{e}_{2}\right) \& \operatorname{BE}\left(\mathrm{e}_{2}, \mathrm{p}\right)$
b. $\llbracket k \operatorname{keep} \rrbracket(x)(p)=$ ?
$\operatorname{Agent}\left(\mathrm{x}, \mathrm{e}_{1}\right) \& \operatorname{CAUSE}\left(\mathrm{e}_{1}, \mathrm{e}_{2}\right) \& \operatorname{BECOME}\left(\mathrm{e}_{2}, \mathrm{p}\right)$
c. $\llbracket \operatorname{keep} \rrbracket(\mathrm{x})(\mathrm{p})=$ ?
$\operatorname{Agent}\left(\mathrm{x}, \mathrm{e}_{1}\right) \& \operatorname{CAUSE}\left(\mathrm{e}_{1}, \mathrm{e}_{2}\right) \& \llbracket \operatorname{stay} \rrbracket\left(\mathrm{e}_{2}, \mathrm{p}\right)$
d. $\llbracket \operatorname{stay} \rrbracket\left(\mathrm{e}_{2}\right)(\mathrm{p}) \neq \mathrm{BE}\left(\mathrm{e}_{2}, \mathrm{p}\right)$

Jackendoff (1987: 375 ) is driven by such considerations to simply posit STAY as a subtype of his 'primitive conceptual category' EVENT. He writes, "The arguments of STAY, which denotes stasis over a period of time, are the Thing standing still and the Place where it is located, as seen in Bill stayed in the kitchen, for instance." The difference between STAY and $\mathrm{BE}$ for him is that BE is a subtype of the conceptual category STATE, not EVENT, but it is not clear what the ingredients of EVENT-hood are, i.e. whether events are constituted by change, energy input, or some other property.

What is needed is a way to represent the idea that keep and stay involve the input of energy into a situation, rather than a change. Following Talmy 1988, we propose that there is exactly a force that maintains p's truth between one situation and the successor situation, against a tendency otherwise.

We follow this intuition informally here, leaving detailed formal denotations and modeltheoretic considerations for when we have developed a full semantic model (Copley \& Harley, in prep). Consider an initial situation $\mathrm{s}$ where $\mathrm{p}$ holds. If $\mathrm{s}$ is a keeping or staying situation, there is a subsituation s' identical to the initial situation in all respects except for the absence of the individuals and/or properties that generate the keeping or staying force. This "agonist" subsituation s' has a net force f' which, when opposed to the "antagonist" net force f'" of the rest

\footnotetext{
${ }^{39}$ Paul Portner (p.c.) suggests the possibility that $s t a y=b e+$ a presupposition that $\mathrm{p}$ is true of the e' immediately preceding $\mathrm{e}_{2}$. Although this idea captures the intuition that stay describes a proposition that persists, it does not in any way address the aspectual distinctions between stay and be, such that stay, like other dynamic predicates, is compatible with the progressive, incompatible with episodic present tense but compatible with habitual present, etc., while be, a stative predicate, shows precisely the opposite characteristics. It would be unusual to attribute such differences to the presence of an additional presupposition.
} 
of s (i.e., the net force of s minus s'), results in a transition to a final situation of which $\sim p$ holds. The net force $\mathrm{f}_{0}$ of $\mathrm{s}_{0}$ is equal to $\mathrm{f}^{\prime}+\mathrm{f}^{\prime}$ ', and can be thought of as having magnitude zero (though strictly speaking magnitudes are not part of the framework). Thus, keeping and staying involve a net force of a situation $\mathrm{s}_{0}$ of which a property $\mathrm{p}$ holds, and whose successor situation $\mathrm{s}_{1}$ would, in the absence of the properties that give rise to the agonist component force $\mathrm{f}^{\prime}$, be a situation of which $\sim$ p holds. Keep and stay hence introduce predicates of forces with the special property that their initial and final situations are identical with respect to $\mathrm{p}$, but which, without the input of the agonist component force, differs with respect to $\mathrm{p}$. In contrast, a stative predicate such as The door (is) open picks out situations to which no force need be added in order for $\mathrm{p}$ to endure over time - that is, they describe a situation of which $\mathrm{p}$ is true, and whose successor situation also has the property $\mathrm{p}$, ceteris paribus.

In the force-theoretic analysis, then, the predicates keep and stay are very similar to the predicates open (transitive) and open (intransitive) above, bearing the same relationship to each other that usual causative/inchoative pairs do (following Jackendoff 1975, 1987, among others). Let us consider stay first, as in The door stayed open. It will take a complement that is a predicate of situations, type $<\mathrm{s}, \mathrm{t}>$, and require that this $<\mathrm{s}, \mathrm{t}>$ complement be true of both the initial situation and the final situation--in effect, a verb-of-maintaining version of $\mathrm{v}_{\mathrm{BECOME}}$. Note that the verb stay is base-generated here in the $\mathrm{v}$ head position, and that the present proposal thus treats it as a light verb; this is in keeping with the treatments in Givón 2001:166, Levin and Rappaport Hovav 2008.

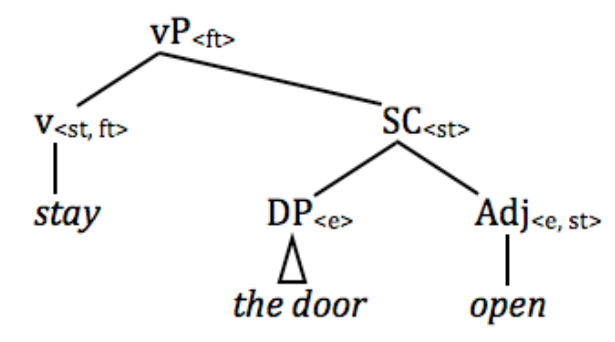

$$
\begin{aligned}
& \llbracket \mathrm{v}_{\text {STAY }} \rrbracket=\lambda \mathrm{p} \lambda \mathrm{f} \cdot \mathrm{p}(\mathrm{fin}(\mathrm{f})) \\
& \text { presupposed: } \mathrm{p}(\operatorname{init}(\mathrm{f}))
\end{aligned}
$$

Keep and stay are then differentiated in the same way as our inchoative/causative pairs above, in that keep includes a VoiceP projection which introduces an external argument and asserts that it is the source of the force; and stay does not. ${ }^{40}$

\footnotetext{
${ }^{40}$ We assume that when keep or stay takes an apparently eventive predicate as its complement, as in John kept Bill running around all day, the aspectual operator represented by -ing has applied to map the $<\mathrm{f}, \mathrm{t}>$ constitutent [run around all day] to an appropriate $<\mathrm{s}, \mathrm{t}>$ predicate.
} 


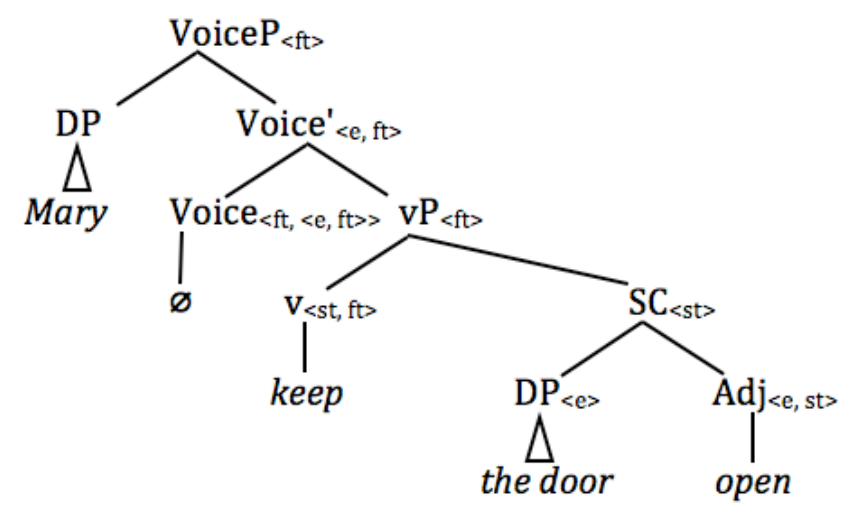

We thus treat keep as a transitive suppletive variant of stay, in the same way that raise is allomorphically related to rise, lay to lie, teach to learn, and feed to eat. Both keep and stay are dynamic predicates, but do not provoke a change. The initial situation $\mathrm{s}_{0}$ has net force which creates a transition to $s_{1}$ but it is a zero magnitude net force and a trivial transition.

This treatment of verbs of maintaining highlights an important distinction between the present force-theoretic approach to dynamicity and recent literature appealing to the Davidsonian event argument in the analysis of a class of predicates which do not entail change but do pattern with more typical dynamic predicates in their interaction with the standard aspectual tests, predicates like sit, stay, lie, etc. (Maienborn (2005, 2007), Rothmayr (2009), Fábregas \& Marín (2012), Moltmann (2013a,b)). The test p happened while... is used (Maienborn 2005: 285, e.g.) to distinguish process predicates from 'Davidsonian' or 'concrete' stative predicates of this kind. Thus if a distinction between kinematics (motion, or more abstractly change) and dynamics (forces) is to be maintained in the terminology (similar to Bach 1986), processes and happenings are not the only predicates which exhibit "dynamicity", as that would improperly exclude the keep, stay, sit... class.

Our system reifies forces not changes; Maienborn's, and other event-based treatments reify changes, not forces. Where we agree is that predicates like keep, stay, sit, stand, etc. have both something in common with "action" predicates like hit, break, laugh (both of us reify this in the type theory) and something in common with Kimian statives such as know French, weigh 1 $\mathrm{kg}$. For us this latter similarity is in the truth conditions of a verb like stay but it is not reified in the ontology. So there is no problem with a class of Davidsonian states being different from a class of processes; we just don't think the relevant property here is visible to type-theory. Rather, it is part of encyclopedic/world knowledge. The failure of happen predication in \#John was sitting on the porch. This happened while... is for us a colorless-green-ideas kind of problem.

\section{Concluding thoughts}

We began the paper with a problem-how to account for the "ceteris non paribus" or "defeasible causation" cases in which the cause happens but the effect does not necessarily occur. We proposed a causal function from situations to situations, to allow reference to the effect without having to assert its existence, and we argued that this function corresponds nicely to the idea of force. The force argument replaces Davidson's event argument in "eventive" (for 
us, "dynamic") predicates.

With this model in mind, we turned to the syntax/semantics interface in order to clarify how the proposed semantics is implemented compositionally in the argument structure, retaining recent advances in the understanding of the substructure of dynamic predicates while accounting for other phenomena which have not previously been amenable to analysis within the eventbased framework, including the dynamic/stative distinction and verbs of maintaining. In developing these proposals, an important advantage of the framework was its ability to make a natural type-theoretic distinction between dynamic and stative predicates: stative predicates are predicates of situations, while dynamic ones are predicates of forces.

We would like to conclude by pointing out several ways in which the force-theoretic framework provides natural divisions of labor between linguistic semantics and other domains, making the case that it represents an advance in carving the world at its joints.

One key shift in emphasis is entirely within the semantics: instead of event arguments and world arguments, the force-theoretic framework uses force arguments and situation arguments (the former, effectively, derived from the latter). As we have suggested, force and situation arguments share some of the work that might otherwise be done by event arguments, since dynamic predicates are predicates of forces and stage-level stative predicates are predicates of events. However, in another sense, the force argument takes on some of the work previously done by world arguments, in handling the ceteris non paribus cases. One reason why such a redivision of labor may be advantageous is that it allows us to construct possible worlds out of causal chains of situations. It is worth considering whether possible worlds might be constructed using the very same elements used to build causal chains in the vP; see Cipria \& Roberts, 2000, and Del Prete, 2012 for accounts involving situations extending into the future, though not exactly as we have done here.

Incorporating causal chains into the framework also has other consequences ripe for future exploration. For example, it allows reference to one argument in terms of another, without the need to bind the argument existentially; instead it is introduced as the result of applying a function to an argument, whether that function is a force or another function such as net, init, or pred. In such a framework, it is not necessary to introduce each such argument via its own functional head (e.g. Borer 2005). The semantics can refer internally to such substructure without imposing the need for a corresponding syntactic projection in each case, taking over some of the work done by individual argument-introducing predicates in syntactic approaches to event decomposition.

Finally, the force-theoretic framework invites a deeper investigation of the division of labor between cognition and the grammar. A mapping between linguistic semantics and a cognitive or conceptual representation has always been necessary, though sometimes this mapping is seen as being trivial or even identity. In the present proposal, because of the dual nature of forces as conceptual forces (perceived inputs of energy) and linguistic forces (functions from situations to situations), there must be a structured conceptual level ("conceptual form"?), that is rather distinct from the logical forms that are the interpretations of linguistic structures. We are pursuing the possibility in other work (Copley \& Harley, in preparation) that modeltheoretic tools can be applied to elucidate a distinct conceptual level in the same way that they make possible an explicit evaluation of the linguistic semantic computation. If this can be done, there is the intriguing possibility of simplifying the semantics by pursuing the idea that much linguistically relevant complexity resides in the cognitive system. 


\section{References}

Abusch, Dorit. 1985. On verbs and time. PhD dissertation, University of Massachusetts at Amherst.

Alexiadou, A, E. Anagnostopoulou \& F. Schäfer. 2006. The properties of anticausatives crosslinguistically. In Phases of Interpretation, ed. M. Frascarelli, Berlin: Mouton de Gruyter.

Alexiadou, A., Anagnostopoulou, E. and Schäfer, F. (to appear). External Arguments in Transitivity Alternations: A Layering Approach, Oxford: Oxford University Press.

Altshuler, D. 2013. There is no neutral aspect. Proceedings of SALT 23: 40-62.

Anscombe, G. E. M. 1971. Causality and Determination. repr. in E. Sosa and M. Tooley (eds). Causation. Oxford: Oxford University Press.

Asher, N. 1992. 'A default, truth-conditional semantics for the progressive', Linguistics and Philosophy, 15, 463-508.

Aristotle. The Internet Classics Archive: http://classics.mit.edu/Aristotle.

Bach, E. 1986. The algebra of events. Linguistics and Philosophy 9 5-16. Dordrecht: Reidel.

Bale, A. \& Barner, D. (2009). The interpretation of functional heads: Using comparatives to explore the mass/count distinction. Journal of Semantics, 26, 217-252.

Bar-El, L., H. Davis and L. Matthewson. 2005. In Bateman, L. and C. Ussery (eds.) NELS 35 : Proceedings of the 35th annual meeting of the North East Linguistics Society, Vol. 1. pp. 87-102.

Barbey, A., \& Wolff, P. 2007. Learning causal structure from reasoning. In Proceedings of the Twenty-Ninth Annual Conference of the Cognitive Science Society. Hillsdale, NJ:

Erlbaum.

Beaver, D. 2001. Presupposition and assertion in Dynamic Semantics. Oxford: Oxford University Press.

Beavers, J. 2011a. On affectedness. Natural Language and Linguistic Theory 29: 335-370.

Beavers, J. 2011b. An aspectual analysis of ditransitive verbs of caused possession in English. Journal of Semantics 28: 1-54.

Beavers, John and Cala Zubair. 2013. Anticausatives in Sinhala: Involitivity and causer suppression. Natural Language and Linguistic Theory 31(1): 1-46.

Bittner, M. (1998). Concealed causatives. Natural language semantics, 7(1), 1-78.

Bobaljik, J. 1994. “What Does Adjacency Do ?” In H. Harley \& C. Phillips, eds., MIT Working Papers in Linguistics vol. 22: The Morphology-Syntax Connection, pp. 1-32.

Bobaljik, J. (2012). Universals in Comparative Morphology: Suppletion, superlatives, and the structure of words. Cambridge: MIT Press.

Bohnemeyer, J. and Swift, M. 2006. 'Force dynamics and the progressive', Proceedings of the Annual Meeting of the Linguistic Society of America, Albuquerque.

Bonomi, A. 1997. 'The Progressive and the Structure of Events', Journal of Semantics, 14, 173205.

Borer, H. 1998. "Passive without Theta Grids", in S.G. Lapointe, D.K. Brentari, and P.M. Farrell, eds., Morphological Interfaces, CSLI Publications, Stanford, CA, 60-99.

Borer, H. 2005. Structuring Sense II: The Normal Course of Events, Oxford University Press, Oxford, UK.

Bruening, B. 2012. By-Phrases in Passives and Nominals. Syntax 16: 1-41.

Chomsky, N. 1995. The Minimalist Program. Cambridge, MA: MIT Press.

Chierchia, G. (1989/2004). A Semantics for Unaccusatives and its Syntactic Consequences. In 
Alexiadou A., Anagnostopoulou E. and M. Everaert, eds., The Unaccusativity Puzzle. Explorations at the Syntax-Lexicon Interface. Oxford: Oxford University Press.

Cipria, A. and C. Roberts. 2000. "Spanish imperfecto and pretérito: Truth Conditions and Aktionsart effects in a Situation Semantics." Natural Language Semantics. 2000 (8). 297347.

Cleland, Carol. 1991. On the individuation of events. Synthese 86, 229-254.

Comrie, B. 1976. Aspect: An introduction to verbal aspect and related problems. Cambridge: Cambridge University Press.

Copley, B. 2002. The semantics of the future. MIT Ph.D. dissertation. Copley, B. 2008. "The plan's the thing: Deconstructing futurate meanings," Linguistic Inquiry 39.2 261-274.

Copley 2009. The semantics of the future. Routledge.

Copley, B. 2010. "Towards a teleological model for modals." Talk presented at the Paris Working Sessions on Modality, Goals and Events, CNRS/ENS/Paris VIII.

Copley, B. 2014. Causal chains for futurates. "Future Time(s) / Future Tense(s)", M. Kissine, P. De Brabanter, Saghie Sharifzadeh (eds.), Future Tense(s) / Future Time(s), Oxford: Oxford University Press.

Copley, B. and H. Harley. 2014. Telicity is launching and atelicity is entrainment. Paper presented at the workshop Dog Days 3, University of Toronto, 7 August 2014. http://bcopley.com/wp-content/uploads/copley.toronto.slides.2014.pdf.

Copley, B. and H. Harley. 2010. "Causatives, ability, and dispositions. Talk presented at the Workshop on Dispositions, Ability, and States of the Project ANR GENIUS (Genericité: Interprétation et Usages).

Copley, B. and H. Harley. In press. "Eliminating causative entailments with the force-theoretic framework: The case of the Tohono O'odham frustrative cem" To appear in Copley, B. and Martin, F. Causation in Grammatical Structures. Oxford University press.

Copley, B. and H. Harley. In preparation. "A force-theoretic semantics." ms. CNRS and University of Arizona.

Copley, B. and P. Wolff. In press. Theories of causation should inform linguistic theory and vice versa. Copley, B. and Martin, F. Causation in Grammatical Structures. Oxford University Press.

Croft, William (1990). 'Possible verbs and the structure of events', in Savas Tsohatzidis (ed.), Meanings and Prototypes: Studies in Linguistic Categorization, London: Routledge, 4873.

Croft, W. 1991. Syntactic Categories and Grammatical Relations: The Cognitive Organization of Information. Chicago: University of Chicago Press.

Croft, William (1998). 'Event structure in argument linking', in Miriam Butt and Wilhelm Geuder (eds.), The Projection of Arguments: Lexical and Syntactic Constraints, Stanford: CSLI Publications, 21-63.

Cuervo, M. C. 2003. Datives At Large. MIT doctoral dissertation.

Dahl, Ö. 2007. "Towards an ecological semantics of tense and aspect." In Aspect in Language and Theories: Similarities and Differences, ed. by Danielle Monticelli and Anu Treikelder, pp. 111-123. Talinn: Tartu.

Davidson, D. 1967. “The Logical Form of Action Sentences.” In N. Rescher (ed.) The Logic of Decision and Action. University of Pittsburgh Press. 81-95.

de Swart, Henriette. 1998. "Aspect shift and coercion." Natural Language and Linguistic Theory, $16.2,347-85$. 
Del Prete, Fabio. (2012). Imperfectivity and Habituality in Italian. In Genericity, A. Mari, C.

Beyssade \& F. Del Prete (eds.), Oxford: Oxford University Press, 222-249.

Dell, François. 1987. "An Aspectual Distinction in Tagalog." Oceanic Linguistics 22-23(1-2) : 175-207.

Dowe, P. 2000. Physical Causation. Cambridge: Cambridge University Press.

Dowty, D. 1979. Word Meaning in Montague Grammar: The Semantics of Verbs and Times in Generative Semantics and in Montague's PTQ. Dordrecht: Springer.

Dowty, David (1991). 'Thematic proto-roles and argument selection', Language, 67, 547- 619.

Eells, Ellery. 1991. Probabilistic Causality. Cambridge: Cambridge University Press.

Embick, David. 2010. Localism vs. Globalism in Morphology and Phonology. Cambridge, MA: MIT Press.

Fábregas, Antonio \& Rafael Marín (2012): State nouns are Kimian states. In I. Franco, S. Lusini \& A. Saab (eds.), Romance Languages and Linguistic Theory 2010. Selected Papers from 'Going Romance' Leiden 2010. Amsterdam, Philadelphia: John Benjamins, 41-64.

Filip, H. 2008. Events and Maximalization. Theoretical and Crosslinguistic Approaches to the Semantics of Aspect, edited by Susan Rothstein. Amsterdam: John Benjamins.Pp.217256.

Fernando, T. 2004. A finite-state approach to events in natural language semantics, Journal of Logic and Computation 14.1, 79-92.

Fernando, T. 2005 Comic relief for anankastic conditionals. In Proceedings of the 15th Amsterdam Colloquium, pp. 71-76

Fodor, Jerry A. 1981. Representations: Philosophical essays on the foundation of cognitive science. Cambridge, MIT: MIT Press.

Folli, Raffaella. 2003. Constructing Telicity in English and Italian. PhD thesis, University of Oxford.

Folli, R. and Harley, H. 2004. "Flavors of v: Consuming results in Italian and English," in Roumyana Slabakova and Paula Kempchinsky, eds., Aspectual Inquiries, 95-120. Dordrecht: Kluwer

Folli, R. and H. Harley. 2008. "Teleology and animacy in external arguments." Lingua 118.2, 190-202.

Folli, R. and H. Harley. 2013. Against deficiency-based typologies: Manner-alternation parameters in Italian and English. Paper presented at WCCFL 31, Arizona State University, Feb 10, 2013.

Freyd, J. F., Pantzer, T. M., \& Cheng, J. L. (1988). Representing statics as forces in equilibrium. Journal of Experimental Psychology: General, 117, 395-407.

Gärdenfors, P. 2004. Conceptual spaces: The geometry of thought. Cambridge, MA: MIT Press. Gärdenfors, P. 2005. The dynamics of thought. Springer.

Gärdenfors, P. 2007. "Representing actions and functional properties in conceptual spaces." In Tom Ziemke, Jordan Zlatev, Roslyn M. Frank, eds., Body, Language, and Mind, Volume 1, Embodiment. Mouton de Gruyter.

Galton, A. (1984). The logic of aspect: an axiomatic approach. OUP.

Giannakidou, A. \& E. Staraki. 2010. "Ability, action, and causation: from pure ability to force." To appear in Mari, A., Beyssade, C. and F. Del Prete, (eds) Genericity. Oxford: OUP.

Giorgi, A. and F. Pianesi, (2001). Ways of Terminating. In C. Cecchetto, G. Chierchia and M.T. Guasti, eds. Semantic Interfaces: Reference, Anaphora and Aspect. CSLI Publications, Stanford. 211-277. 
Givón, T. 2001. Syntax, Vol 1. Amsterdam: John Benjamins.

Glasbey, S. 1996. "The Progressive: a Channel-Theoretic Analysis." Journal of Semantics 13.4: 331-361.

Godfrey-Smith, P. 2009. Causal pluralism. In H. Beebee, C. Hitchcock, P. Menzies (eds.) The Oxford Handbook of Causation, pp 326-337. Oxford: OUP

Groenendijk, J. and M. Stokhof 1991. "Dynamic Predicate Logic". Linguistics and Philosophy 14: 39-100.

Hale, Kenneth and Keyser, Samuel (1993). 'On argument structure and the lexical expression of syntactic relations', in Kenneth Hale and Samuel Keyser (eds.), The View from Building 20: Essays in Linguistics in Honor of Sylvain Bromberger, Cambridge: MIT Press, 53109.

Hall, Ned (2004). 'Two Concepts of Causation', in John Collins, Ned Hall and Laurie Paul (eds.), Causation and Counterfactuals, Cambridge: MIT Press, 225-276.

Halle, Morris and Alec Marantz. (1993). Distributed Morphology and the pieces of inflection. In K. Hale and S. J. Keyser, A View from Building 20. Cambridge, MA: MIT Press. pp. 111176

Harley, H. 2005. How Do Verbs Get Their Names? Denominal Verbs, Manner Incorporation, and the Ontology of Verbs Roots in English. In The Syntax of Aspect: Deriving Thematic and Aspectual Interpretation, N. Erteschik-Shir \& T. Rapoport (eds.), 42-64. Oxford (New York): Oxford University Press.

Harley, H. 2012a. External arguments and the Mirror Principle: On the distinctness of Voice and v. Lingua 125: 34-57.

Harley, H. 2012b. "Semantics in Distributed Morphology." In Semantics: An International Handbook of Natural Language Meaning. C. Maienborn, K. von Heusinger and P. Portner, eds. Berlin: Mouton de Gruyter, 2151-2172

Hasegawa, Y. (1996). The (nonvacuous) semantics of TE-linkage in Japanese.Journal of Pragmatics, 25(6), 763-790.

Hay, J, C. Kennedy, and B. Levin. 1999. ' Scalar Structure Underlies Telicity in 'Degree Achievements"', Proceedings of SALT 9, Cornell Linguistics Circle Publications, Cornell University, Ithaca, NY, 127-144.

Hegarty, M. (2004). Mechanical reasoning by mental simulation. Trends in cognitive sciences, $8(6), 280-285$

Heim, I. 1982. The Semantics of Definite and Indefinite Noun Phrases. Ph.D. thesis, University of Massachusetts, Amherst.

Herweg, M. (1991). Perfective and imperfective aspect and the theory of events and states. Linguistics, 29(6), 969-1010.

Higginbotham, J. 1985. On semantics. Linguistic Inquiry 16, 547-593.

Higginbotham, J. 2000. “Accomplishments.” In Proceedings of 2nd GLOW in Asia, 131-139. Nanzan University, Japan. Also published as Higginbotham, J. 2009.

"Accomplishments." In Tense, Aspect and Indexicality, 116-125. Oxford: OUP.

Hobbs, Jerry R. 2005. "Toward a Useful Concept of Causality for Lexical Semantics" Journal of Semantics 22: 181-209.

Holmes, K., \& Wolff, P. (2010). Simulation from schematics: Dorsal stream processing and the perception of implied motion. To appear in R. Catrambone \& S. Ohlsson (Eds.), Proceedings of the 32nd Annual Conference of the Cognitive Science Society. Austin, TX: Cognitive Science Society. 
Holmes, K. J., \& Wolff, P. (2013). Spatial language and the psychological reality of schematization. Cognitive processing, 14(2), 205-208.

Hoekstra, T. and R. Mulder. 1990. Unergatives as copular verbs: Locational and existential predication. The Linguistic Review 7: 1-79.

Hoekstra, T. 1984. Transitivity: Grammatical relations in Government-Binding Theory. Dordrecht: Foris Publications.

Jackendoff, R. 1975. "A system of semantic primitives." In R. Schank and B. Nash-Webber (eds.) Theoretical Issues in Natural Language Processing. ACL, Arlington VA.

Jackendoff, R. 1987. The status of thematic relations in linguistic theory. Linguistic Inquiry 18.3, 369-411.

Jackendoff, R. 1990. Semantic Structures. Cambridge, MA: MIT Press.

Jackendoff, R. 1991. 'Parts and Boundaries,' Cognition 41, 9-45.

Jackendoff, R. 1997. The Architecture of the Language Faculty. Cambridge, MA: MIT Press.

Kallulli, D. 2006. A unified analysis of passives, anticausatives and reflexives. In O. Bonami \& P. Cabredo Hofherr (eds.) Empirical Issues in Formal Syntax and Semantics 6: 201-225.

Kamp, H. (1979), 'Events, Instants and Temporal Reference', in R. Bäuerle et al (eds.) Semantics from Different Points of View, Springer, Berlin, pp. 376-417.

Kamp, H. 1981. "A theory of truth and semantic representation”. In: J.A.G. Groenendijk, T.M.V. Janssen, and M.B.J. Stokhof (eds.), Formal Methods in the Study of Language. Mathematical Centre Tracts 135, Amsterdam. Pp. 277-322.

Kamp, H. 2007. Intentions, Plans, and Their Executions: Turning Objects of Thought into Entities in the External World. ms.

Kamp, H. and U. Reyle. 1993. From Discourse to Logic. Dordrecht: Kluwer.

Katz, G. 2003. 'Event arguments, adverb selection, and the Stative Adverb Gap'. In E. Lang, C. Maienborn \& C. Fabricius-Hansen (eds.) Modifying Adjuncts. (Interface Explorations 4), 455-474. Berlin: Mouton de Gruyter.

Kistler, M. 2006. Causation and Laws of Nature. New York: Routledge.

Kearns, K., S., 1991. The Semantics of the English Progressive. Ph.D. Thesis, MIT, Cambridge MA.

Kennedy, C. and B. Levin (2008) 'Measure of Change: The Adjectival Core of Degree Achievements", in L. McNally and C. Kennedy, eds., Adjectives and Adverbs: Syntax, Semantics and Discourse, Oxford University Press, Oxford, UK, 156-182.

Kennedy, C. and L. McNally. (2005) Scale structure, degree modification and the semantic typology of gradable predicates. Language, 81(2):345-381.

Kennedy, C. in press. The Composition of Incremental Change. In Demonte, V. and L. McNally (eds), Telicity, Change, State: A Cross-categorical View of Event Structure. Oxford: Oxford University Press.

Kiparsky, Paul. 1997. Remarks on Denominal Verbs. In Alex Alsina, J. Bresnan and P. Sells (eds.), Argument Structure. 473-499. Stanford: CSLI, 1997

Klein, 1994. Time in Language. London: Routledge.

Koenig, J.P \& L.-C. Chief. 2007. "Scalarity and state-changes in Mandarin (and other languages)" In Empirical Issues in Syntax and Semantics 7, ed. by Olivier Bonami and Patricia Cabredo Hofherr. 241-262. Paris: CSSP.

Koenig, J.P. and A. R. Davis. 2001. Sublexical modality and the structure of lexical semantic representations. Linguistics and Philosophy 24: 71-124.

Koenig, Jean-Pierre and Nuttanart Muansuwan. 2000. How to end without ever finishing: Thai 
semi-perfective markers. Journal of Semantics, 17:147-184.

Koontz-Garboden, Andrew. 2009. Anticausativization. Natural Language and Linguistic Theory 27.

Kratzer, A. 1989. "An investigation of the lumps of thought." Linguistics \& Philosophy 12: 607653.

Kratzer, A. 1991. Modality. In: A. von Stechow \& D. Wunderlich (eds.). Semantik: Ein internationales Handbuch zeitgenössischer Forschung. Berlin: Mouton de Gruyter, 639650.

Kratzer, A. 1996. "Severing the external argument from its verb." In Johann Rooryck and Laurie Zaring, eds., Phrase Structure and the Lexicon, 109-137, Dordrecht: Kluwer.

Kratzer, A. 1998. "More structural analogies between pronouns and tenses." In Proceedings of SALT VIII. CLC Publications.

Kratzer, Angelika. 2005. 'Building resultatives', in C. Maienborn \& A. Wöllstein (eds.), Event arguments: foundations and applications, Tübingen: Max Niemeyer Verlag, 177-212.

Kratzer, Angelika. 2013. "Creating a family. Talk presented at Workshop on Little v, University of Leiden, October 2013.

Krifka, Manfred. (1989). Nominal reference, temporal constitution and quantification in event semantics In Renate Bartsch, J. F. A. K. van Benthem \& P. van Emde Boas (eds.), Semantics and Contextual Expression. Foris Publications. 75--115 (1989)

Krifka, Manfred (1992). 'Thematic relations as links between nominal reference and temporal constitution', in Ivan Sag and Anna Szabolsci (eds.), Lexical Matters, Stanford: CSLI Publications, 29-53.

Krifka, M. 1998. 'The origins of telicity', in Susan Rothstein (ed.), Events and Grammar, Dordrecht: Kluwer Academic Publishers, 197-235.

Lambalgen, M. van and F. Hamm. 2003. "Event calculus, nominalisation, and the progressive," Linguistics and Philosophy 26.4, pp 381-458.

Lambalgen, M van and F. Hamm. 2005. The Proper Treatment of Events. Oxford: Blackwell Publishers.

Landman Fred. 1992. "The progressive." Natural Language Semantics 1:1 1-32.

Langacker, Ronald W. 1991. Foundations of Cognitive Science, Volume II. Palo Alto: Stanford University Press.

Leslie, A. M., \& Keeble, S. (1987). Do six-month old infants perceive causality? Cognition, 25, 265-288.

Levin, B. and M. Rappaport Hovav (2005) Argument Realization, Research Surveys in Linguistics Series, Cambridge University Press, Cambridge, UK.

Levin, B. and Malka Rappoport Hovav. 1995. Unaccusativity. At the Syntax-Lexical Semantics Interface. Cambridge, MA: MIT Press

Levin, B. and Malka Rappaport Hovav. 2008. "Lexical Conceptual Structure." in K. von Heusinger, C. Maienborn, and P. Portner, eds., Semantics: An International Handbook of Natural Language Meaning, Mouton de Gruyter, Berlin.

Levin, B. and M. Rappaport Hovav. 2010 "Lexicalized Scales and Verbs of Scalar Change", Lewis, David. 1973. Causation. The Journal of Philosophy, 556-567.

Levinson, Lisa. 2007. The Roots of Verbs. Ph.D. dissertation, New York University.

Lombard, L. 1979. Events. Canadian Journal of Philosophy, Vol. 9, No. 3 (Sep., 1979), pp. 425- 
460

Maienborn, Claudia (2005): On the Limits of the Davidsonian Approach: The Case of Copula Sentences. Theoretical Linguistics 31: 275-316.

Maienborn, Claudia (2007): On Davidsonian and Kimian states. In I. Comorovski \& K. v. Heusinger (eds.), Existence: Semantics and Syntax. Dordrecht: Kluwer, 107-130.

Marantz, Alec. 1984. On the nature of grammatical relations. Cambridge, Mass.: MIT Press.

Marantz, A. 2001. Words. Ms., NYU. http://ling.ucsc.edu/ hank/mrg.readings/Marantz_words.pdf

Marantz, Alec. 1997. 'No escape from syntax: Don't try morphological analysis in the privacy of your own Lexicon.' Proceedings of the 21st Annual Penn Linguistics Colloquium: Penn Working Papers in Linguistics 4: 2, ed. Alexis Dimitriadis et.al. 201-225.

Marín, Rafael \& Louise McNally. 2011. Inchoativity, change of state, and telicity: Evidence from Spanish reflexive psychological verbs. Natural Language and Linguistic Theory 29, 467-502.

Matthewson, Lisa. 2004. "Cross-linguistic variation and the nature of aspectual classes. Handout of talk given at Cornell University, February 26, 2004.

Matushansky, Ora. 2006. "Head movement and linguistic theory." Linguistic Inauiry 37.1 69-109

McCawley, J. D. 1971. Pre-Lexical Syntax. In O’Brien, R. (ed.), Report of the 22nd Roundtable Meeting on Linguistics and Language Studies. Georgetown: Georgetown University Press, pp. 19-33.

McCawley, J. D. 1976. "Remarks on what can cause what." In M. Shibatani (ed), The grammar of causative constructions. New York: Academic Press. pp. 117-129.

McClure, W. 1994. Syntactic Projections of the Semantics of Aspect. Ph.D. dissertation, Cornell University.

Michotte, A. 1946/1963. The perception of causality. Methuen: London.

Moens, M., \& Steedman, M. (1988). Temporal ontology and temporal reference. Computational Linguistics, 14(2), 15-28.

Moltmann, Friederike. "The semantics of existence." Linguistics and philosophy 36.1 (2013): 3163.

Moltmann, Friederike (2013): On the Distinction Between Abstract States, Concrete States, and Tropes. In A. Mari, C. Beyssade \& F. Del Prete (eds.), Genericity. Oxford: Oxford University Press, 292-311.

Montague, Richard. 1970. Pramatics and intensional logic, Synthese 22: 68-94. [Reprinted in R. Montague, Formal philosophy, Chap. 4. Yale University Press, New Haven, 1974.]

Mumford, Stephen, and Anjum, Rani Lill. 2011. Getting Causes from Powers. Oxford: Oxford University Press.

Naumann, R. 2001. Aspects of changes: a dynamic event semantics. J Semantics 18.1: 27-81

Naumann, R. and C. Pinon. 1997. Decomposing the progressive, in Proceedings of the Eleventh Amsterdam Colloquium, Paul Dekker, Martin Stokhof, and Yde Venema (eds.), ILLC/Department of Philosophy, University of Amsterdam, 241-246.

Nishiyama, A. 2006. The Meaning and Interpretations of the Japanese Aspect Marker -te-i-. Journal of Semantics 23:2, 185-216.

Ogihara, Toshiyuki. (1998) "The Ambiguity of the -te iru Form in Japanese," Journal of East Asian Linguistics 7, 87-120.

Paramasivam, K. P. 1977. Effectivity and causativity in Tamil. Doctoral dissertation, University. Parsons, T. 1989. "The progressive in English: Events, states, and processes." Linguistics and 
Philosophy 12: 213-241.

Parsons, T. 1990. Events in the Semantics of English. Cambridge: MIT Press.

Partee, B. 1977. "John is easy to please," in A. Zampolli (ed.), Linguistic Structures Processing, North Holland, Amsterdam, 281-312.

Partee, B. H. (1989). Possible worlds in model-theoretic semantics: A linguistic perspective. Possible Worlds in humanities, arts and sciences, Berlin, Walter de Gruyter, 93-123.

Pearl, J. 2000. Causality: Models, Reasoning, and Inference. Cambridge: Cambridge University Press.

Piñón, Christopher. 1997. Achievements in an event semantics. In Proceedings of Semantics and Linguistic Theory VII, eds. A. Lawson and E. Cho, 273-296. Ithaca, NY: CLC Publications.

Piñón, C. 2001. A finer look at the causative/inchoative alternation. Proceedings of Semantics and Linguistic Theory 11, Rachel Hastings, Brendan Jackson, and Zsofia Zvolenszky (eds.), CLC Publications, Cornell University, Ithaca, NY.

Piñon, C. 2008. 'Aspectual composition with degrees.' In Adjectives and Adverbs: Syntax, Semantics, and Discourse, Louise McNally and Christopher Kennedy (eds.), pp. 183219. Oxford University Press.

Portner, P. 1998. The progressive in modal semantics. Language 74: 760-787.

Prince, A. and P. Smolensky. 1993/2004. Optimality Theory: Constraint interaction in generative grammar. Cambridge, MA: Blackwell Publishers.

Pustejovsky, J. 1991. The syntax of event structure. Cognition 41: 47-81.

Pustejovsky, J. 1995. The Generative Lexicon. Cambridge, Massachusetts : MIT Press.

Pylkkänen, L., 2002. Introducing Arguments. Ph.D. Thesis. MIT. Cambridge, MA. Distributed by , Cambridge, MA

Pylkkänen, L., Martin, A. E., McElree, B., \& Smart, A. 2009. The Anterior Midline Field: Coercion or Decision Making? Brain and Language, 108, 184-90

Ramchand, G. 1997. Aspect and Predication:The Semantics of Argument Structure. Oxford: Oxford University Press.

Ramchand, G. 2008. Verb meaning and the lexicon: A first-phase syntax. Cambridge University Press.

Rappaport Hovav, M. (2008) "Lexicalized Meaning and the Internal Temporal Structure of Events," in S. Rothstein, ed., Theoretical and Crosslinguistic Approaches to Aspect, John Benjamins. 13-42

Rappaport Hovav, M., \& Levin, B. 2001. An event structure account of English resultatives. Language, 77, 766-797.

Reichenbach, H. 1971 The Direction of Time. Berkeley and Los Angeles: University of California Press. Originally published 1956.

Reinhart, Tanya. 2000. The Theta System: syntactic realization of Verbal concepts OTS working papers. TL-00.002, Utrecht University.

Rosen, S. T. 1999. The syntactic representation of linguistic events. GLOT International, 4.2, pp 3-11.

Rothmayr, Antonia (2009): The Structure of Stative Verbs. Amsterdam, Philadelphia: John Benjamins.

Rothstein, S. (2008). Structuring events: A study in the semantics of aspect(Vol. 5). John Wiley $\&$ Sons.

Roy, I. \& E. Soare (2013). “Event related Nominalizations”. In: G. Iordăchioaia, I. Roy \& K. 
Takamine (Eds.) Categorization and Category Change, Cambridge Scholars Publishing, Cambridge.

Saxe, R and Carey, S. 2006. The perception of causality in infancy. Acta Psychologica 123 (2006) 144-165.

Schachter, Paul and Fe Otanes. 1972. Tagalog Reference Grammar. Berkeley, CA: University of California Press.

Schäfer, F. 2007. On the nature of anticausative morphology: External arguments in change-ofstate contexts. Doctoral Dissertation, University of Stuttgart.

Schäfer, F. \& Vivanco, M. 2013. Reflexively marked anticausatives are not semantically reflexive. Talk given at Going Romance, Amsterdam.

Shibatani, M. 1973. A linguistic study of causative constructions. Doctoral dissertation, University of California Berkeley.

Singh, Mona (1998). 'On the semantics of the perfective aspect', Natural Language Semantics, $6,171-199$.

Smith, C. 1983. A theory of aspectual choice. Language 59: 3, 479-501

Smith, C. 1991/1997. The Parameter of Aspect. Dordrecht: Kluwer Academic Press.

Suppes, P. 1970. A Probabilistic Theory of Causality. Amsterdam: North-Holland Publishing Company.

Talmy, Leonard. 1976. 'Semantic causative types' In Shibatani (ed.), Syntax and semantics Vol. 6: The grammar of causative constructions. New York: Academic Press.

Talmy, Leonard. 1981. 'Force Dynamics'. Paper presented at conference on Language and Mental Imagery. May 1981, University of California, Berkeley.

Talmy, Leonard. 1985a. 'Force Dynamics in language and thought' In Papers from the Regional Meetings, Chicago Linguistic Society, 21, 293-337.

Talmy, Leonard. 1985b. 'Force Dynamics as a generalization over causative' In Georgetown University Round Table on Languages and Linguistics, 67-85.

Talmy, Leonard. 1988. "Force dynamics in language and cognition." Cognitive Science 12:49100

Talmy, Leonard. 2000. Toward a cognitive semantics. Cambridge, MA: MIT press.

Tatevosov, S. (2008). 'Subevental structure and non-culmination', in O. Bonami and P. Cabredo Hofherr (eds), Empirical Issues in Syntax and Semantics 7, http://www.cssp.cnrs.fr/eiss7, 393-422.

Tedeschi, P. J. 1973. 'Some suggestions for a Semantic Analysis of Progressives,' University of Michigan Papers in Linguistics 1.2, 157-168.

ter Meulen, A. 1985. Progressives without possible worlds, in William Eilfort, Paul Kroeber, and Karen Peterson. (eds.), Chicago Linguistic Society 21, part 1, 259-280.

ter Meulen, A. 1990. English aspectual verbs as generalized quantifiers. In Proceedings of the Seventh Amsterdam Colloquium, pp. 303-315. University of Amsterdam.

Thomason, R. 1970. Indeterminist time and truth-value gaps. Theoria 18:3, pp. 264-281.

Thomason, R. and Robert Stalnaker 1973 A semantic theory of adverbs. Linguistic Inquiry 4.2, 195-220.

Tovena, Lucia. 2011. Accomplishments: their telos and their structure. In Reich, Ingo et al. (eds.), Proceedings of Sinn \& Bedeutung 15, pp. 1-15. Universaar - Saarland Unversity Press: Saarbrücken, Germany.

Travis, L. 2000. Event structure in syntax. In C. Tenny \& J. Pustejovsky, (Eds.), Events as grammatical objects: The converging perspectives of lexical semantics and syntax, 145- 
185. Stanford, CA: CSLI Publications.

Van Valin, Robert D. Jr. 1990. Semantic parameters of split intransitivity. Language 66: 221260.

Van Valin, Robert D. and Randy J. LaPolla. 1997. Syntax: Structure, Meaning and Function. Cambridge: Cambridge University Press.

Vecchiato, Antonella. 2003. The Italian periphrastic causative and force dynamics. USC Working Papers in Linguistics Vol. 1. ed. by F. Nihan Ketrez, Justin M. Aronoff, Monica Cabrera, Asli Ciger, Shadi Ganjavi, Milena Petrova, Isabelle Roy. 91-109.

Vecchiato, Antonella. 2004. On intentional causation in Italian. In Contemporary Approaches to Romance Linguistics, ed. by Julie Auger, J. Clancy Clements, Barbara Vance, pp 343360. Amsterdam: John Benjamins.

Vendler, Zeno (1957). 'Verbs and times', The Philosophical Review, 66, 143-160.

Verkuyl. H. J. 1972. On the Compositional Nature of the Aspects, Reidel, Dordrecht.

Vlach, Frank. 1981. The semantics of the progressive. In Syntax and semantics, vol. 14: Tense and aspect, ed. P. J. Tedeschi and Annie Zaenen, New York: Academic Press 271-292.

Walsh, C. and S. Sloman. 2011. The Meaning of Cause and Prevent: The Role of Causal Mechanism Mind \& Language, Vol. 26, No. 1 February 2011, pp. 21-52.

White, P. A. 2011. Visual impressions of force exerted by one object on another when the objects do not come into contact, Visual Cognition, 19:3, 340-366

Williams, Edwin. 1981. Argument Structure and Morphology. The Linguistic Review 1, 81-114.

Wolff, P. \& Song. G. 2003. Models of causation and the semantics of causal verbs. Cognitive Psychology, 47. pp. 276-332.

Wolff, P. 2007. Representing causation. Journal of Experimental Psychology: General, 136, 82111.

Wolff, P., Barbey, A. K., \& Hausknecht, M. 2010. For want of a nail: How absences cause events. Journal of Experimental Psychology: General, 191-221.

Wolff, P., Hausknecht, M., \& Holmes, K. 2011. Absent causes, present effects: How omissions cause events. In J. Bohnemeyer \& E. Pederson (Eds.), Event representation in language: Encoding events at the language cognition interface. Cambridge: Cambridge University Press, 228-252.

Wolff, P. In press. Causal pluralism and force dynamics. In Copley, B. and F. Martin, eds., Causation in Grammatical Structures. Oxford: OUP.

Woodward, James. 2009. 'Agency and interventionist theories', in Helen Beebee, Christopher Hitchcock and Peter Menzies (eds.), The Oxford Handbook of Causation, Oxford: Oxford University Press, 234-262.

Zacks, J.M., Kurby, C.A., Eisenberg, M.L., Haroutunian, N. 2011. Prediction error associated with the perceptual segmentation of naturalistic events. Journal of Cognitive Neuroscience, 23,4057-4066.

Zwarts, Joost. (2010). Forceful prepositions. In Vyvyan Evans and Paul Chilton, eds., Language, Cognition and Space: The State of the Art and New Directions. Equinox Publishing, 193214. 